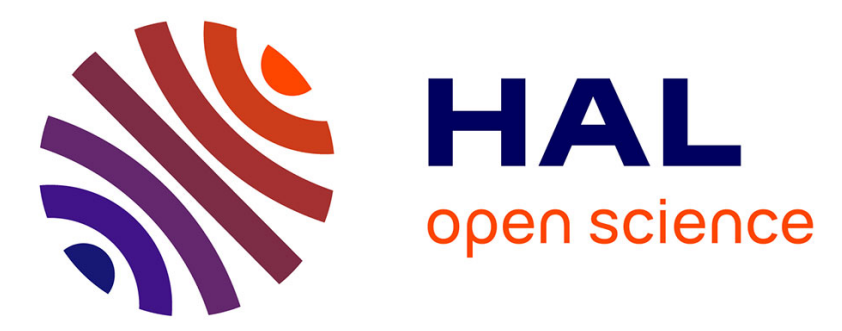

\title{
Molecular environment of iodine in naturally iodinated humic substances: Insight from X-ray absorption spectroscopy
}

Michel L. Schlegel, Pascal E. Reiller, Florence F. Mercier-Bion, Nicole Barré, Valérie Moulin

\section{To cite this version:}

Michel L. Schlegel, Pascal E. Reiller, Florence F. Mercier-Bion, Nicole Barré, Valérie Moulin. Molecular environment of iodine in naturally iodinated humic substances: Insight from X-ray absorption spectroscopy. Geochimica et Cosmochimica Acta Supplement, 2006, 70 (22), pp.5536-5551. 10.1016/j.gca.2006.08.026 . cea-01270133

\section{HAL Id: cea-01270133 https://hal-cea.archives-ouvertes.fr/cea-01270133}

Submitted on 5 Feb 2016

HAL is a multi-disciplinary open access archive for the deposit and dissemination of scientific research documents, whether they are published or not. The documents may come from teaching and research institutions in France or abroad, or from public or private research centers.
L'archive ouverte pluridisciplinaire HAL, est destinée au dépôt et à la diffusion de documents scientifiques de niveau recherche, publiés ou non, émanant des établissements d'enseignement et de recherche français ou étrangers, des laboratoires publics ou privés. 


\title{
Molecular environment of iodine in naturally iodinated humic substances: Insight from X-ray absorption spectroscopy
}

\author{
Michel L. Schlegel ${ }^{\mathrm{a}, *}$, Pascal Reiller ${ }^{\mathrm{b}}$, Florence Mercier-Bion ${ }^{\mathrm{a}, 1}$, \\ Nicole Barré ${ }^{\mathrm{a}, 1}$, Valérie Moulin ${ }^{\mathrm{c}}$ \\ a Laboratory for the Reactivity of Surfaces and Interfaces, Commissariat à l'énergie atomique, CEN of Saclay, \\ Bât. 391; F-91191 Gif-sur-Yvette Cedex, France \\ ${ }^{\mathrm{b}}$ Laboratory for the Speciation of Radionuclides and Molecules, Commissariat à l'énergie atomique, CEN of Saclay, \\ Bât. 391; F-91191 Gif-sur-Yvette Cedex, France \\ " Commissariat à l'énergie atomique, Nuclear Energy Division, DDIN \& UMR 8587 “Analyse et Environnement" (CEA/CNRS/UEVE); \\ CEN of Saclay, F-91191 Gif-sur-Yvette Cedex, France
}

Received 17 February 2006; accepted in revised form 21 August 2006

\begin{abstract}
The molecular environment of iodine in reference inorganic and organic compounds, and in dry humic and fulvic acids (HAs and FAs) extracted from subsurface and deep aquifers was probed by iodine $\mathrm{L}_{3}$-edge X-ray absorption spectroscopy. The X-ray absorption near-edge structure (XANES) of iodine spectra from HAs and FAs resembled those of organic references and displayed structural features consistent with iodine forming covalent bonds with organic molecules. Simulation of XANES spectra by linear combination of reference spectra suggested the predominance of iodine forming covalent bonds to aromatic rings (aromatic-bound iodine). Comparison of extended X-ray absorption fine structure (EXAFS) spectra of reference and samples further showed that iodine was surrounded by carbon shells at distances comparables to those for references containing aromatic-bound iodine. Quantitative analysis of EXAFS spectra indicated that iodine was bound to about one carbon at a distance $d(\mathrm{I}-\mathrm{C})$ of 2.01(4)-2.04(9) $\AA$, which was comparable to the distances observed for aromatic-bound iodine in references (1.99(1)-2.07(6) $⿱$ ), and significantly shorter than that observed for aliphatic-bound iodine $(2.15(2)-2.16(2) \AA$ ). These results are in agreement with previous conclusions from X-ray photoelectron spectroscopy and from electrospray ionization mass spectrometry. These results collectively suggest that the aromatic-bound iodine is stable in the various aquifers of this study.
\end{abstract}

(C) 2006 Elsevier Inc. All rights reserved.

\section{Introduction}

Iodine is an essential trace element for living organisms, and must be taken up at significant doses (e.g., $100 \mu \mathrm{g}$ daily) to prevent such deficiency-related diseases as goiter. In absence of iodine supplementation by iodinated salt, most of iodine intake is provided by the diet, and therefore assessing the bioavailability of dissolved iodine is essential (Cooksey, 1985; Guetat et al., 1990;

\footnotetext{
* Corresponding author. Fax: +33169085411.

E-mail address: michel.schlegel@cea.fr (M.L. Schlegel).

${ }^{1}$ Present address: Institut de Physique nucléaire d'Orsay, 15, Rue G. Clemenceau, F-91406 Orsay Cedex, France.
}

Andersen et al., 2002). Understanding the mechanisms governing iodine bioavalability is also required to predict the impact of iodine radioisotopes $\left({ }^{131} \mathrm{I}\right.$ and $\left.{ }^{129} \mathrm{I}\right)$ released into the environment as a result of nuclear testing, processing of nuclear fuel (Raisbeck and Yiou, 1999; Frechou and Calmet, 2003), and nuclear accidents such as Kyshtym-Chelyabinsk (Goldman, 1997), Windscale (Stewart and Crooks, 1958), and Chernobyl (Devell et al., 1986; Hou et al., 2003; Kashparov et al., 2005). On the one hand, ${ }^{131}$ I is extremely harmful (Shibata et al., 2001), but short-lived $\left(\tau_{1 / 2}=8\right.$ days $)$. On the other hand, ${ }^{129} \mathrm{I}$ is long-lived $\left(\tau_{1 / 2}=1.57 \times 10^{7}\right.$ years $)$, and its release from spent nuclear fuel can lead to contamination of sediments (Matishov et al., 2002), coastal areas (Frechou and 
Calmet, 2003), and soils surrounding nuclear facilities (Stewart and Wilkins, 1985; Robens et al., 1989), which makes this radionuclide of particular environmental concern (Guetat et al., 1990).

Past studies have suggested that iodine retention, transport, and ultimately bioavailability in natural environments are strongly affected by the iodine speciation. Iodine in natural waters is known to exist as both inorganic (iodide and iodate) and organic-bound forms (Stipanicev and Branica, 1996; Yamada et al., 1999; Andersen et al., 2002). Fuge (1996) observed that soils with neutral to slightly basic $\mathrm{pH}$ were much enriched in iodine, compared to neighboring acidic soils. Fuge (1996) explained this correlation between $\mathrm{pH}$ and iodine content by the stabilization in basic soils of iodate, which is more easily retained by organic matter and clay particles than iodide, which is stable in acidic soils. Interestingly, iodine immobilization and reduced bioavailability also increased with the organic matter in soil (Fuge, 1996). Iodine speciation was also shown to affect the transport of this element in soil columns, as organic-bound iodine was strongly retarded with respect to iodate and iodide, suggesting preferential fixation of organically bound iodine in soils (Hu et al., 2005). Indeed, a significant, sometimes predominant, proportion of dissolved iodine was found to be associated with natural organic matter (NOM) (Lunde, 1929; Sheppard and Thibault, 1992; Sheppard et al., 1995; Chagué-Goff and Fyfe, 1996; Ashworth et al., 2003; Bostock et al., 2003), and specifically humic substances (HS), both in ocean and terrestrial waters (Francois, 1987; Bors et al., 1988; Wong and Cheng, 1998; Rädlinger and Heumann, 2000), including groundwater (Andersen et al., 2002). However, no consensus exists on the molecular mechanism of iodine interaction with NOM (Johanson, 2000). Sheppard and Thibault (1992) proposed that iodine was retained mostly by physical association with surfaces and entrapment in NOM micropores, although they recognized that some iodine was also bound to HS. In contrast, Whitehead (1974) suggested that molecular iodine in solution $\left(\mathrm{I}_{2}(\mathrm{aq})\right)$ in equilibrium with iodide $\left(\mathrm{I}^{-}\right)$would react with amino acids and phenolic compounds in soils. Clearly, distinct mechanisms of retention would lead to distinct paths of iodine remobilization in the environment, and therefore a better knowledge of the processes of iodine retention by organic molecules is warranted.

Insight on the mechanism of iodine retention by NOM, and specifically humic acids (HA) and fulvic acid (FA), has been gained by characterizing the oxidation state and molecular speciation of iodine in iodinated organic matter. X-ray photoelectron spectroscopy (XPS) has been used on naturally iodinated humic substances (NIHS) and valuable information on the formal oxidation degree $\left(v_{\mathrm{I}}\right)$ and chemical environment of iodine has been obtained (Mercier et al., 2000, 2002). Direct analysis of HA iodinated in laboratory (Moulin et al., 2001) has been performed by electrospray ionization mass spectrometry (ESI-MS) which revealed molecular association at high iodine content (up to $10 \mathrm{wt} \%$ ), after a short contact time.
Additional information on the iodine speciation in both iodine-concentrated and iodine-diluted samples may be obtained using spectroscopic tools specifically designed to probe the molecular environment of dilute elements, such as X-ray absorption spectroscopy (XAS). The X-ray absorption near-edge structure (XANES) can provide information on the oxidation state, electronic structure, and chemical environment of iodine in NIHS. The extended X-ray absorption fine structure (EXAFS) provides insight into the nature and distance of neighboring atoms (Stern, 1988). To our knowledge, only a few studies have used the discriminating power of XAS to speciate iodine in complex systems (Fuhrmann et al., 1998; Reed et al., 2002; Yamaguchi et al., 2006), and none to NIHS. Hence in this study, XAS has been used to identify the iodine molecular environment and the chemical nature of the iodine-organic bonds in samples of NIHS collected in both subsurface and deep aquifers. Knowledge of this speciation will help to assess the long-term mobility of organically bound iodine in aquifers.

\section{Background}

The reaction of iodine with HS can follow three pathways: (i) methylation of inorganic iodine by biomass (Tessier et al., 2002), (ii) iodination of phenolic moieties (Lee, 1967), and (iii) iodination of amines (Brezonik, 1994). It is well known that halogens can react with phenolic moieties through an electrophilic substitution mechanism (Lee, 1967). For example, reaction of $\mathrm{I}_{2}$ (aq) with phenols in the inevitable presence of HIO can lead to the substitution of a hydrogen by an iodine atom in ortho and para position of the phenolic ring, and to the release of $\mathrm{HI}$ in solution. A similar reaction has been identified for chlorine and iodine during disinfection of drinking waters by hypohalogenous acids (Bichsel and von Gunten, 1999). For this mechanism to be effective, the halogen atom needs to be in its $+\mathrm{I}$ redox state (HIO). This substitution reaction is also observed for enzymatic cycles involved in the regulation of hydrogen peroxide (Wagenknecht and Woggon, 1997). Another possible reaction is the halogenation of amines, which can be written: $\mathrm{NH}_{3}+n \mathrm{HOX} \rightleftarrows \mathrm{NH}_{3-n} \mathrm{X}_{n}+n \mathrm{H}_{2} \mathrm{O}$, where $n=1$ or 2 , and $\mathrm{X}$ is a halogen. In that case, the halogen is also present at the $+\mathrm{I}$ oxidation state but does not induce the formation of a halogenide ion as in electrophilic substitution.

Laboratory experiments on purified organic fractions of soils and sediments were performed to gain additional insight into the interaction mechanism(s) of iodine and natural organic matter. Francois (1987) observed that iodate $\left(\mathrm{IO}_{3}^{-}\right)$was readily retained by sedimentary HS, whereas little reaction was observed with iodide. This latter point was confirmed by Reiller and Moulin (2003) using $\mathrm{Na}_{2} \mathrm{~S}_{2} \mathrm{O}_{3}$ to stabilize $\mathrm{I}^{-}$. Francois (1987) proposed a reaction scheme whereby iodate would be reduced to an electrophilic species, i.e., $\mathrm{I}_{2}(\mathrm{aq})$ or $\mathrm{HIO}$, that would later react with NOM (Truesdale, 1974). This reaction is likely considering 
the range of redox properties of HS proposed in the literature (Skogerboe and Wilson, 1981; Österberg and Shirshova, 1997). Warner et al. (2000) confirmed that $\mathrm{I}_{2}$ (aq) uptake by substituted phenol compounds could be correlated to the degree of electrophilic substitution on these moieties and observed rate laws comparing well with those for NOM. Note that this mechanism can lead to multiple substitution on the phenolic rings and to the oxidation of the aromatic structure, ultimately releasing trihalomethanes (Rook, 1974; Bichsel and von Gunten, 2000).

Francois (1987) also showed that much of HS-associated iodine could be removed by the action of nucleophiles such as $\mathrm{OH}^{-}$or thiosulfates. A comparable instability of radiolabelled organic matter was observed by Dierckx et al. (1998) after reaction with chloramines T. This suggests that the electrophilic substitution is not the only reaction involved in the iodine retention mechanism by NOM. As a matter of fact, only a stronger electrophile than $\mathrm{I}(+1)$ can induce a substitution reaction on phenolic moieties. In contrast, the decomposition of dichloroamine can occur simply in neutral or basic medium, under conditions for which electrophilic substitution is irreversible. Thus, in the case of Dierckx et al. (1998), the electrophilic substitution is not the only reaction involved in the iodine retention mechanism by NOM.

\section{Materials and methods}

\subsection{Origin and extraction of naturally iodinated humic substances (NIHS)}

Five aquatic humic substances including HA and FA from four distinct locations and a variety of terrestrial/geologic environments were studied in this work. They originate from a former uranium mine in a granitic environment at Fanay-Augères (Limousin, France) (Moulin et al., 1991, 1996); from a subsurface aquifer located in an Apto-Albian sandy formation in the East of the Paris Basin at Soulaines (France); from the Rupelian aquifer at the bottom of the Boom clay formation hosting the Boom underground laboratory at Mol (Belgium) (Montjotin, 1996); and from deep iodine-rich brines of marine origin at Mobara (Japan) (Muramatsu et al., 2001).

The extraction and purification methods of humic substances have been detailed in Moulin et al. (1991) and Dellis and Moulin (1989) for the granitic water (FanayAugères), and in Montjotin (1996) for sand (Mol) and subsurface (Soulaines) aquifers. The principle of the isolation method is based on concentration of humic substances from the aquifer water either on an anionic exchange resin (DEAE resin) for Fanay-Augères and Soulaines samples, or on a non-ionic resin (XAD-8 resin) for the Mol and Mobara samples. Mobara samples (Japan) were kindly provided by Dr. S. Nagao (JAERI, Japan). Table 1 lists the elementary composition and iodine content of the probed NIHS. The measured iodine concentration in FA_Fanay was measured using neutron activation analysis
(Mercier et al., 2000) and equals 679(68) ppm (Table 1), slightly greater than the quantification limit of XAS ( $\sim 100 \mathrm{ppm}$ at the iodine $\mathrm{L}_{3}$-edge). The concentrations in FA_Soulaines, FA_Mobara, and HA_Mobara, HA_Mol were estimated from the intensity of the iodine fluorescence and comparison with organic references, and equal $\sim 0.6$, $\sim 4, \sim 10$, and $\sim 0.4 \mathrm{wt} \%$, respectively (Table 1 ).

\subsection{Selection of iodine references}

Several solid structural references, both inorganic and organic, were selected to determine the sensitivity of XAS to variations in $v_{\mathrm{I}}$, local environments, and iodine chemistry. Potassium iodide (KI) and sodium iodide $(\mathrm{NaI})$ were chosen to represent $v_{\mathrm{I}}=-1$, and potassium iodate $\left(\mathrm{KIO}_{3}\right)$ to represent $v_{\mathrm{I}}=5$. Bisublimed $\mathrm{I}_{2}(\mathrm{cr})$ was selected as a prototype of iodine at $v_{\mathrm{I}}=0$ and not associated with NOM. Organic references (Table 2) were chosen to represent the diversity of functional groups possibly encountered in the NIHS structure (Fig. 1). Recent works performed by ESI-MS (Plancque et al., 2001) or 2D RMN (Simpson, 2001) have shown that FA are composed of aggregates of many small molecules (200-800 atomic mass unit, amu) probably linked by hydrogen or weak bonds to form supramolecules (see also Sutton and Sposito, 2005). The proposed structures of various aquatic FA are made by phenolic cores binding with carboxylic moieties as well as amino groups (Plancque et al., 2001). Thus, selected structural references contain iodine forming covalent bonds either with aliphatic chains or aromatic rings substituted by distinct functional groups representative of those found in humic substances (phenolic, carboxylic, alcoholic, methoxy or amine). In contrast with previous spectroscopic studies using XPS, some solid references with low temperatures of sublimation could be analyzed with XAS, as this technique is not subject to severe sublimation limitations.

\subsection{X-ray absorption spectroscopy}

Iodine $\mathrm{L}_{3}$-edge XAS spectra for NIHS were collected in fluorescence mode at the ID26 beamline (undulator source) of the European Radiation Synchrotron Facility (ESRF, France). The storage ring was operated at electron energy of $6 \mathrm{GeV}$ and a ring current between 200 and $100 \mathrm{~mA}$. Higher harmonics were rejected using a flat Si mirror, the X-ray energy of the incident beam was selected with a $\mathrm{Si}(111)$ double crystal monochromator cooled to $\sim 133 \mathrm{~K}$, and the beam was focused by a pair of bent mirrors ( $\mathrm{Si}$ and fused silica). The monochromator was calibrated by using a Ti foil and setting the first maximum of the Ti edge at $4966.8 \mathrm{eV}$. This calibration was checked every two or three spectra by running a NaI reference. No significant change in the position of the iodine edge was observed. The intensity of the incident beam and of the fluorescence signal was monitored by using diode array and silicon drift detectors, respectively. Silicon drift detectors have a high counting rate and, 
Table 1

Characteristics of naturally iodinated organic matter (NIOM) probed in this study

\begin{tabular}{llllllll}
\hline Sample & {$[\mathrm{C}](\mathrm{wt} \%)$} & {$[\mathrm{H}](\mathrm{wt} \%)$} & {$[\mathrm{O}](\mathrm{wt} \%)$} & {$[\mathrm{N}](\mathrm{wt} \%)$} & {$[\mathrm{S}](\mathrm{wt} \%)$} & {$[\mathrm{I}](\mathrm{wt} \%)$} & Analytical technique for determination of I content \\
\hline FA_Fanay & 49.2 & 4.8 & 44.7 & 1.4 & 1.0 & 0.07 & $\mathrm{NAA}^{\mathrm{a}}$ \\
FA_Soulaines & 52.1 & 5.0 & 40.3 & 1.2 & 1.4 & 0.6 & $\mathrm{XRF}^{\mathrm{b}}$ \\
FA_Mobara & & & & & 6 & $\mathrm{XRF}^{\mathrm{b}}$ \\
HA_Mobara & & & & & & 10 & $\mathrm{XRF}^{\mathrm{b}}$ \\
HA_Mol & 69.2 & 6.5 & 20.1 & 2.7 & 1.5 & 0.4 & $\mathrm{XRF}^{\mathrm{b}}$ \\
\hline
\end{tabular}

${ }^{a}$ Neutron activation analysis (Mercier et al., 2000).

${ }^{\mathrm{b}}$ Estimated from the intensity of iodine X-ray fluorescence (XRF) and organic references.

Table 2

List of reference solids for X-ray absorption spectroscopy

\begin{tabular}{|c|c|c|c|}
\hline Reference & Chemical name & Recording mode & XAS beamline \\
\hline \multicolumn{4}{|l|}{ Inorganics } \\
\hline NaI(hydr) & Sodium iodide hydrated & Fluorescence & ID26 (ESRF) \\
\hline $\mathrm{KI}$ & Potassium iodide anhydrous & Fluorescence & ID26 (ESRF) \\
\hline $\mathrm{I}_{2}(\mathrm{cr})$ & Di-iodine & Fluorescence & ID26 (ESRF) \\
\hline $\mathrm{KIO}_{3}$ & Potassium iodate & Fluorescence & ID26 (ESRF) \\
\hline \multicolumn{4}{|l|}{ Organics } \\
\hline $1 \mathrm{I} 18 \mathrm{C}$ & 1-Iodooctadecane & Fluorescence & ID26 (ESRF) \\
\hline 2IBZA & 2-Iodobenzoic acid & Transmission & D44 (LURE) \\
\hline 2IHIP & 2-Iodohippuric acid & Transmission & D44 (LURE) \\
\hline $2 \mathrm{~N} 5 \mathrm{IB}$ & 2-Amino,5-iodobenzoic acid & Fluorescence & ID26 (ESRF) \\
\hline 3IBZA & 3-Iodobenzoic acid & Fluorescence & ID26 (ESRF) \\
\hline 4I2MP & 4-Iodo,2-methyl phenol & Fluorescence & ID26 (ESRF) \\
\hline 4IBEE & 4-Iodobenzyl ethanol & Transmission & D44 (LURE) \\
\hline 4IANL & 4-Iodoaniline & Fluorescence & ID26 (ESRF) \\
\hline 4IANS & 4-Iodoanisole & Transmission & D44 (LURE) \\
\hline 4IBZA & 4-Iodobenzoic acid & Fluorescence & ID26 (ESRF) \\
\hline 4IPHL & 4-Iodophenol & Transmission & D44 (LURE) \\
\hline 4ITOL & 4-Iodotoluene & Fluorescence & ID26 (ESRF) \\
\hline 5IURA & 5-Iodouracyl & Transmission & D44 (LURE) \\
\hline DIFLU & Diiodo-fluoresceine & Transmission & D44 (LURE) \\
\hline IBZPT & $N$-(3-Iodobenzyl)phthalimide & Transmission & D44 (LURE) \\
\hline IACET & Iodoacetic acid & Transmission & D44 (LURE) \\
\hline
\end{tabular}

because of their small size, they can be positioned a few $\mathrm{mm}$ from the sample, thereby limiting fluorescence absorption by air. Samples were slightly pressed as $\sim 2$-mm-thick pellets and positioned in the X-ray beam, but upstream of the focusing point to limit beam damage. No kapton tape was used on the beam-directed face of the sample, as kapton adsorbed most of the iodine fluorescence, and may react chemically with iodine compounds. Between four and seven scans were collected for each sample, and compared online to check for any beam damage. Only minute variations in the intensity and none in the position of XANES bands could be observed. To limit this potential damage, though, samples were moved under the beam, restoring the original XAS patterns.

Iodine $\mathrm{L}_{3}$-edge $\mathrm{X}$-ray absorption spectra were collected in fluorescence mode under the same experimental conditions, for selected references diluted in boron nitride to limit self-absorption effects. No variations in the intensity and position of XANES bands were observed, except for $\mathrm{I}_{2}(\mathrm{cr})$ that sublimated under the X-ray beam. Therefore, only a noisy XANES spectrum, and no reliable EXAFS data, could be collected for $\mathrm{I}_{2}(\mathrm{cr})$. A second set of XAS data for reference compounds was collected in transmission mode on D44 station (bending magnet source) at the Laboratoire pour l'utilisation du rayonnement électromagnétique (LURE; Orsay, France), with a ring energy and current of $1.85 \mathrm{GeV}$ and $\sim 300 \mathrm{~mA}$, respectively. The beam energy was selected with a $\mathrm{Si}(111)$ double crystal monochromator, and higher harmonics were rejected with a pair of borosilicate mirrors. The intensity of the incident and transmitted beams was measured using low-pressure airfilled ionization chambers. Spectra were calibrated by measuring the X-ray absorption edge of a Ti foil placed between the second and a third ionization chamber, and setting the first edge maximum at $4966.8 \mathrm{eV}$. Comparable spectra were collected at LURE and ESRF (see electronic annex), confirming that the spectral resolution was essentially limited more by the width of the $\mathrm{L}_{3}$-edge $(3.08 \mathrm{eV})$ (Krause and Oliver, 1979) than by the spectrometer resolution. This comparison also demonstrates that we successfully limited self-absorption effects in fluorescence mode. Therefore, spectra collected on two distinct stations 


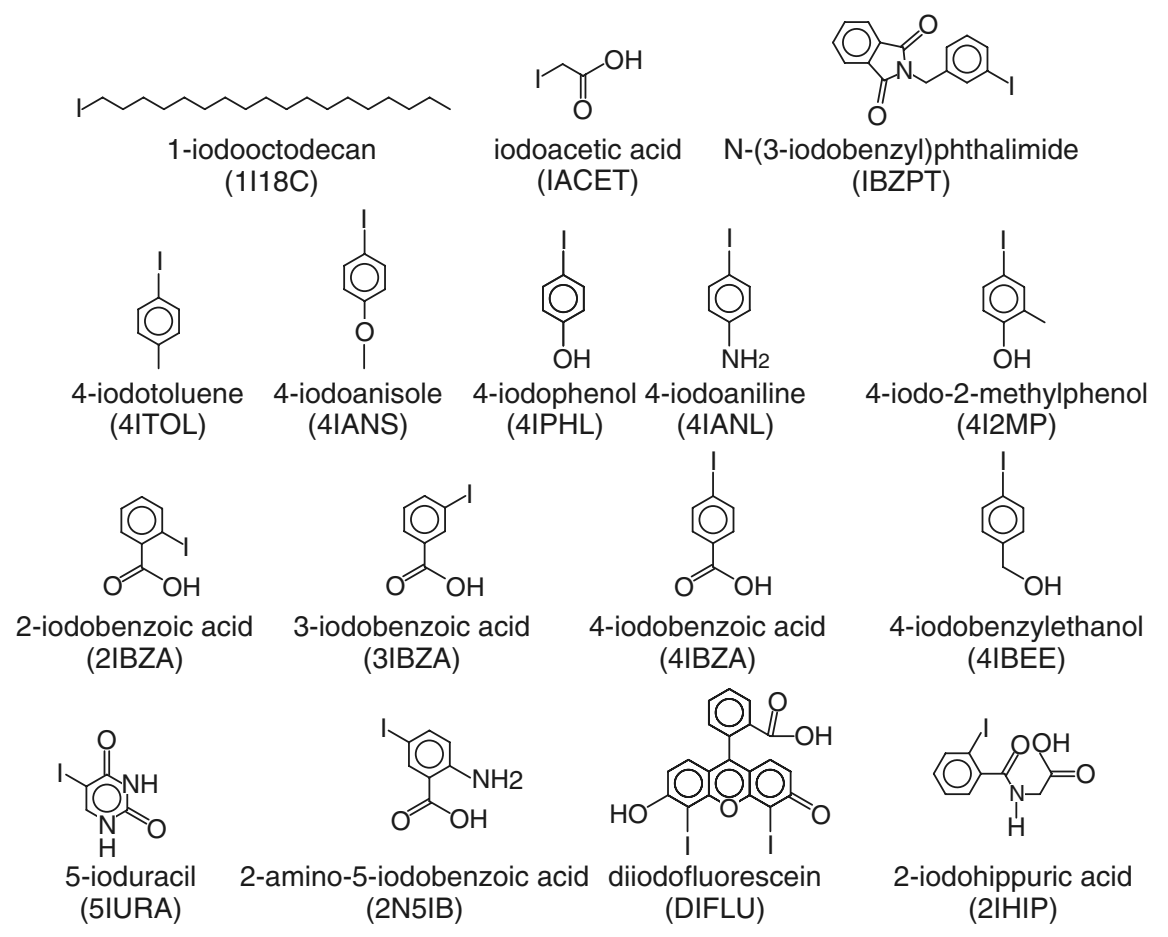

Fig. 1. Molecular structure of iodinated organic compounds used as structural references.

can be all used together to derive information on the structural environment of iodine in the natural samples.

X-ray absorption near-edge structure (XANES) spectra were extracted from the raw XAS data with the SEDEM software (Aberdam, 1998). The pre-edge and post-edge portions of the spectra were fitted with a straight line and a cubic spline, respectively, and the absorption edges normalized for atomic absorption using a six-parameter polynomial fit to the output of the Crome-Liberman $f^{\prime}$ function (Aberdam, 1998). The XANES spectra for HS samples and references were then interpolated to a common abscissa grid, and then the sample spectra were tentatively fitted by linear combination of reference spectra. To minimize the degree of freedoms, only the proportion (relative amplitude) of each reference spectrum was allowed to vary in the fit. The non-linear least-square fitting routine SOLVER of Microsoft Excel ${ }^{\circledR}$ was used to minimize the parameter

$R_{\mathrm{f} 1}=\frac{\left(\sum_{i}\left(\mu_{i}^{\mathrm{lc}}-\mu_{i}^{\exp }\right)^{2}\right)}{\left(\sum_{i}\left(\mu_{i}^{\exp }\right)^{2}\right)}$,

where $\mu_{i}^{\exp }$ is the experimental X-ray absorption spectrum and $\mu_{i}^{\mathrm{lc}}=\sum_{j} X_{j} \mu_{j}$ the linear combination of $\mu_{\mathrm{j}}$ spectra of references $j$. The fractional contributions $X_{j}$ from all species were constrained to $X_{j} \geqslant 0$. In a typical fitting round, all $X_{j}$ were freely adjusted first. Then, all $X_{j}$ of lowest value were successively set to 0 , and the sample spectrum was modeled by adjusting the remaining contributions, until a significant increase in $R_{\mathrm{f} 1}$ (of about $20 \%$ ) was observed. Such an increase was shown to coincide with removal of significant species (Isaure et al., 2002). The uncertainty on the fractional contributions was evaluated by moving and fixing $X_{j}$, and then letting all other parameters float during the fitting procedure. A significant increase in $R_{\mathrm{f} 1}$ of about $20 \%$ was observed for $X_{j}$ variations of \pm 0.2 from the best-fit value.

Extended X-ray absorption fine structure (EXAFS) spectra were extracted using the Athena interface to Ifeffit (Newville, 2001; Ravel and Newville, 2005), using the Autobk routine (Newville et al., 1993). The Autobk algorithm extracts the EXAFS signal with a spline that minimizes the low- $\mathrm{R}$ portion of the Fourier transform (FT) that is not directly related to the presence of backscattering shells. The EXAFS spectra were apodized with a Kaizer-Bessel window (weight $=2$ ), and Fourier-transformed. The FT modules display amplitude maxima (peaks) at apparent distances $(R+\Delta R)$ which differ from the EXAFS path lengths ( $R$, equal to crystallographic absorber-backscatterer distances for single-scattering) by $\sim-0.3 \AA$, owing to phase shifts of the EXAFS waves (Teo, 1986). Selected FT peaks were Fourier back-transformed and fitted by using phases and amplitude functions that have been calculated with FEFF7 (Ankudinov and Rehr, 1997), and crystallographic data for NaI, KI (Wyckoff, 1963), $\mathrm{KIO}_{3}$ (Lucas, 1984), and ethyl 2-formamido-2(4-iodobenzyl)-3-(4-iodophenyl) propanoate (Damodharan et al., 2003). The amplitude reduction factor $\left(S_{0}^{2}\right)$ was set to 1.0 in order to correctly reproduce the number of neighboring atoms in the structural references. For all samples, the statistical uncertainty resulting from spectral noise was calculated by FEFFIT built-in procedures. Note that this 
uncertainty does not account for the accuracy of fitted values which can be guessed only by comparing the values obtained with EXAFS spectroscopy and with other more accurate techniques. However, it can be anticipated that systematic errors similarly affect all fitted parameters for references and samples, and so these fitted parameters may be compared for relative changes.

\section{Results and interpretation}

\subsection{X-ray absorption spectroscopy of structural references}

\subsubsection{X-ray absorption near-edge structure}

Fig. 2 shows that XANES spectra for all inorganic references display peaks at $\sim 4563.6$ and $\sim 4572-4573 \mathrm{eV}$. A comparable $\mathrm{L}_{3}$-edge structure, with first and second peaks near 1555 and $\sim 1565 \mathrm{eV}$, respectively, was observed for
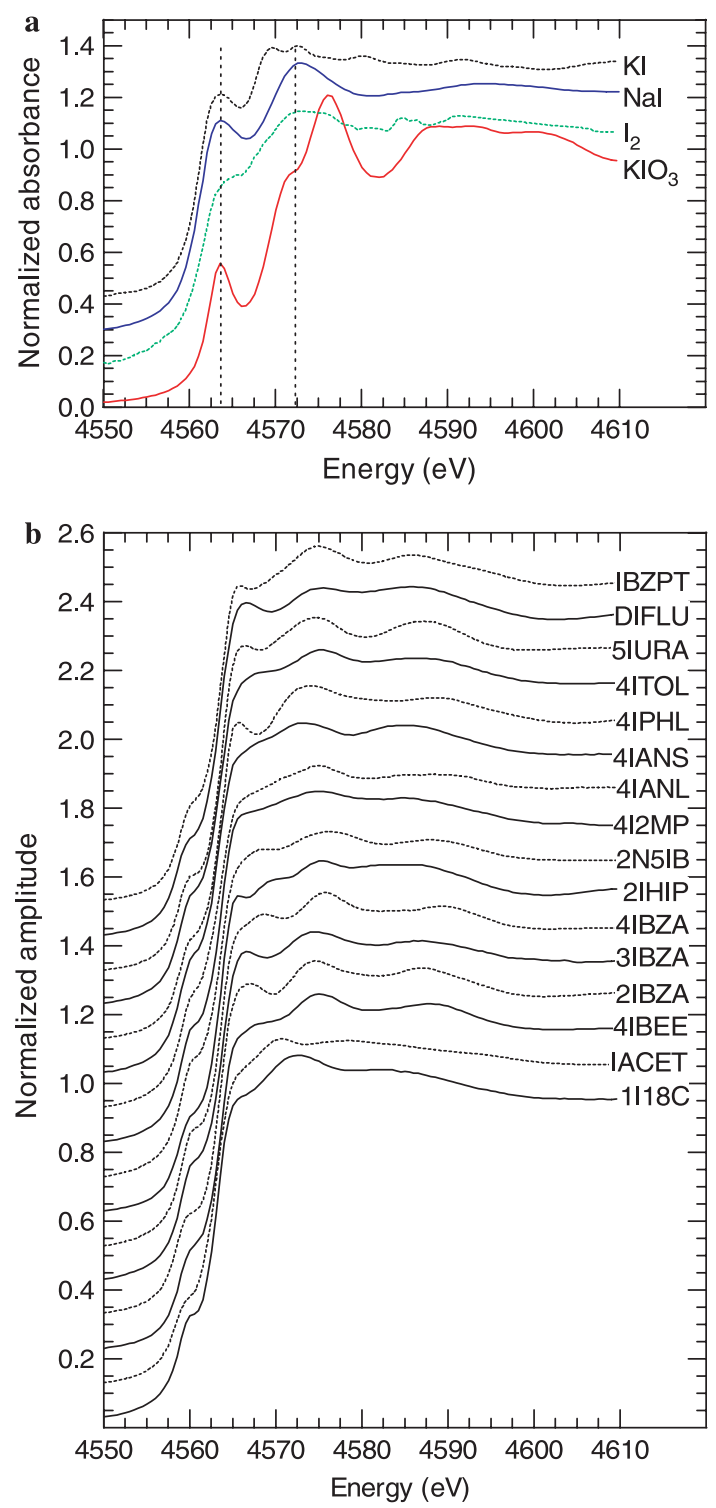

Fig. 2. Iodine $\mathrm{L}_{3}$-edge XANES spectra of reference compounds. (a) Inorganic solids. (b) Organic compounds. bromine in alkali bromine and bromate salts (Matsuo et al., 2003). In this previous study, these edge peaks were related to transitions from the $2 \mathrm{p}_{1 / 2}$ core level to empty $t_{2 \mathrm{~g}}$ (non-bonding) and $\mathrm{e}_{\mathrm{g}}$ (antibonding) sublevels resulting from a split of the $4 \mathrm{~d}$ electronic level in non-planar, cubic symmetry of the bromine references (Rivail, 1989). Molecular-orbital calculations confirmed these assumptions and showed that contributions of $2 p \rightarrow 6 s$ transitions to the overall X-ray absorption of bromine were of marginal importance (Matsuo et al., 2003). By reference to bromine, the absorption peaks at 4563.5 and $\sim 4572-4573 \mathrm{eV}$ in iodine salts are attributed to transitions to $5 \mathrm{~d}$ sublevels. Note that the difference in energy between $t_{2 g}$ and $e_{g}$ sublevels $(\sim 9-10 \mathrm{eV})$ compares favorably with that observed for bromine ( 7.5-12 eV) (Matsuo et al., 2003), hinting at comparable ligand fields in the two series of compounds. Several absorption bands can also be observed at energies $\geqslant 4576 \mathrm{eV}$, in numbers and positions unique to each solid. Interestingly, fewer bands are observed for hydrated $\mathrm{NaI}$ than for crystalline anhydrous $\mathrm{KI}$ and $\mathrm{KIO}_{3}$ (Fig. 2). A similar decrease in the number of XANES bands was observed upon bromine hydration.

Visual inspection of Fig. 2a suggests that the main absorption edge shifts to higher energies with increasing $v_{\text {I }}$. This dependence causes the apparent amplitude of the peak at $4563.5 \mathrm{eV}$ to decrease from $\mathrm{KI}$ and $\mathrm{NaI}$ to $\mathrm{I}_{2}(\mathrm{cr})$, and to $\mathrm{KIO}_{3}$. This edge shift can be traced by the shift of the half-height of the normalized absorption edge, from 4561.0(1) eV in NaI and 4560.9(1) eV in $\mathrm{KI}\left(v_{\mathrm{I}}=-1\right)$ to $4561.4(1) \mathrm{eV}$ in $\mathrm{I}_{2}(\mathrm{cr})\left(v_{\mathrm{I}}=0\right)$ and to $4568.1(1) \mathrm{eV}$ in $\mathrm{KIO}_{3}\left(v_{\mathrm{I}}=5\right)$. This dependence of the edge position with the formal oxidation state is well documented (Brown et al., 1988), and is related to a decrease in the screening of the atomic core by valence electrons, resulting in a greater attraction of remaining electrons. The measured edge positions relatively to $\mathrm{I}_{2}(\mathrm{cr})$ agree within $0.5 \mathrm{eV}$ with relative positions of Fuhrmann et al. (1998), except for liquid $\mathrm{KI}$, for which an edge position at $0.5 \mathrm{eV}$ above $\mathrm{I}_{2}(\mathrm{cr})$ was reported. This discrepancy may result from differences in preparation conditions, as Fuhrmann et al. (1998) collected the KI XANES spectrum on a solution prepared 3-5 days before measurements, possibly allowing iodine oxidation prior to X-ray measurements. However, Wong (1991) reported this reaction to be extremely slow in the absence of catalysts.

In contrast to inorganic references, the main absorption edges for all organic compounds display similar shapes (Fig. 2b). Energies at the jump half-height span only a narrow interval between 4562.3(1) and $4563.0(1) \mathrm{eV}$, i.e., close to the value for $I_{2}(\mathrm{cr}$ ) (Table 3 ). This suggests that iodine with $v_{I}=0$ prevails in all of these references. Also, spectra for all organic references display an absorption shoulder near $4560 \mathrm{eV}$. This shoulder is located at a lower energy than the first peak of all inorganic references, including the reduced ones. Interestingly, a comparable lower energy of the first absorption feature was observed at the chlorine K-edge 
Table 3

Energy position (in $\mathrm{eV}$ ) of iodine $\mathrm{L}_{3}$-edge main peaks and shoulders on XANES spectra for inorganic and organic references

\begin{tabular}{|c|c|c|c|c|c|c|c|c|c|}
\hline Reference & Edge & $A^{s}$ & $\mathrm{~B}$ & $\mathrm{C}$ & $\mathrm{D}$ & $\mathrm{E}$ & $\mathrm{F}$ & $\mathrm{G}$ & $\mathrm{H}$ \\
\hline \multicolumn{10}{|l|}{ Inorganics } \\
\hline NaI(hydr) & 4561 & & 4563.5 & & 4573 & & & & 4594 \\
\hline KI & 4560.9 & & 4563.5 & 4569.5 & 4572 & 4580 & & & \\
\hline $\mathrm{I}_{2}(\mathrm{cr})$ & 4563 & 4559.5 & & $4565.6^{\mathrm{s}}$ & 4573.5 & & 4585 & & \\
\hline $\mathrm{KIO}_{3}$ & 4568.1 & & 4563.5 & & $4572^{\mathrm{s}}$ & 4576 & 4589 & 4592.6 & 4600 \\
\hline \multicolumn{10}{|l|}{ Organics } \\
\hline $1 \mathrm{I} 18 \mathrm{C}$ & 4562.4 & 4558.8 & & 4565.8 & 4572.6 & & 4582 & & \\
\hline 2IBZA & 4562.6 & 4560 & & 4566.6 & 4574.4 & 4586.8 & & & \\
\hline 2IHIP & 4562.8 & 4560 & & 4565.6 & 4569.8 & 4575.2 & 4585.2 & & \\
\hline 3IBZA & 4562.6 & 4560 & & 4566.6 & 4574.4 & 4586.6 & & & \\
\hline 4I2MP & 4562.5 & 4560 & & 4566.2 & & 4574.8 & 4584.6 & & \\
\hline 4IBEE & 4562.8 & 4560 & & 4565.6 & 4567.8 & 4575 & 4587.8 & & \\
\hline 4IANL & 4562.5 & 4560 & & 4566.2 & & 4575 & 4588 & & \\
\hline 4IANS & 4562.3 & 4560 & & 4565.6 & 4568.4 & 4573 & & & \\
\hline 4IBZA & 4562.7 & 4560 & & $4565.8^{\mathrm{s}}$ & 4568.4 & 4575.8 & 4589 & & \\
\hline 4IPHL & 4562.8 & 4560 & & 4567.6 & & 4575 & 4586.4 & & \\
\hline 4ITOL & 4562.5 & 4560 & & 4567.6 & & 4575.5 & 4586.4 & & \\
\hline 5IURA & 4563.0 & 4560 & & 4566.4 & & 4574.4 & 4587.2 & & \\
\hline $2 \mathrm{~N} 5 \mathrm{IB}$ & 4562.5 & 4560 & & 4568.8 & & 4576.2 & 4588 & & \\
\hline DIFLU & 4562.6 & 4560 & & 4566.6 & & 4575.2 & 4585.2 & & \\
\hline IBZPT & 4562.8 & 4560 & & 4565.6 & & 4575 & 4585.8 & & \\
\hline 1IACET & 4562.5 & 4559.8 & & $4565.4^{\mathrm{s}}$ & 4570.2 & 4578 & & & \\
\hline
\end{tabular}

Uncertainties are $\pm 0.1 \mathrm{eV}$ for edge position, and $\pm 0.5 \mathrm{eV}$ for peak and shoulders.

$\mathrm{s}$ Absorption features appearing as shoulders of main peaks.

(Myneni, 2002a,b). This shoulder must result from transition toward an empty molecular orbital with s- or d-like character, but with greater stability than in the ionic solids. To better constrain the nature of this empty level, let us determine the nature of molecular orbitals as a combination of atomic orbitals in iodinated organic compounds (Rivail, 1989; Atkins, 1994). The covalent bond between iodine and the organic molecule likely originates from hybridization of the iodine $5 \mathrm{p}, 6 \mathrm{~s}$ and carbon $2 \mathrm{~s}$ and $2 \mathrm{p}$ atomic orbitals to create $\sigma$-like (axial) and $\pi$-like (lateral) molecular orbitals. Formation of these covalent bonds decreases the energy of the bonding $\sigma$ and $\pi$ orbitals, and increases the energy of the antibonding $\sigma^{*}$ and $\pi^{*}$ levels, relatively to $5 \mathrm{~s}$ and $6 \mathrm{p}$ orbitals in free (atomic) iodine. Because all the $\sigma$ and $\pi$ orbitals between iodine and the molecule are filled with electrons, a significant transition to an s-like state is not expected to occur at energies lower than in the iodine salt. However, due to their symmetry, $5 \mathrm{~d}$ orbitals are expected to mix only marginally to these molecular orbitals, meaning that their energy should not be affected too much by the formation of covalent bonds. The energy of $5 \mathrm{~d}$ orbitals should therefore be more affected by repulsion with surrounding atoms and anions, an effect which is anticipated to be stronger in ionic solids and in solutions than in organic solids (Rivail, 1989; Atkins, 1994). Therefore, the shoulder at $4560 \mathrm{eV}$ may be tentatively assigned to iodine $2 p \rightarrow 5 d$ transitions, and the low energy of this shoulder may reflect the decrease in $5 \mathrm{p}$ levels repulsions in organic compounds relative to aqueous and crystal compounds.
The post-edge XANES spectra of all organic references display at least three main bands near 4566, 4575, and $4585 \mathrm{eV}$ (Fig. 2b and Table 3). These bands reveal the presence of empty states of s- and d-like character, as anticipated from the hybridization of carbon and iodine electronic levels to form $\sigma^{*}$ and $\pi^{*}$ orbitals. Some of the investigated references have unique distributions in peak positions (e.g., iodoacetic acid; IACET); whereas, for others, similarities in peak position and amplitude can be noted (e.g., 2- and 3iodobenzoic acid; 2IBZA and 3IBZA, respectively). These spectral comparisons point to the limited but real sensitivity of iodine $\mathrm{L}_{3}$-edge XANES spectroscopy to the chemical and electronic properties of the iodinated molecules. Therefore, XANES spectroscopy may be used to fingerprint the iodine chemical environment, but this speciation is univocal only in specific cases.

\subsubsection{Extended $X$-ray absorption fine structure}

Fig. 3 shows that the spectral dissimilarities observed for the X-ray absorption edges of inorganic and organic references are echoed by discrepancies in position and amplitudes of $k^{3}$-weighted EXAFS $(\chi(k))$ oscillations. For example, the amplitude of EXAFS oscillations for $\mathrm{KIO}_{3}$ dwarfs those for the other references (Fig. 3a). Spectra for $\mathrm{KI}$ and $\mathrm{NaI}$ also differ from each other, with the hydrated $\mathrm{NaI}$ paralleling $\mathrm{KIO}_{3}$. In contrast, $\chi(k)$ for organic iodinated compounds all display oscillation maxima near 2.5, 4.7, and $6.5 \AA^{-1}$, that may be related to similar EXAFS waves backscattered in these compounds (Fig. 3a). However, small discrepancies in the amplitude and position of secondary EXAFS oscillations can be noted among organic references. 

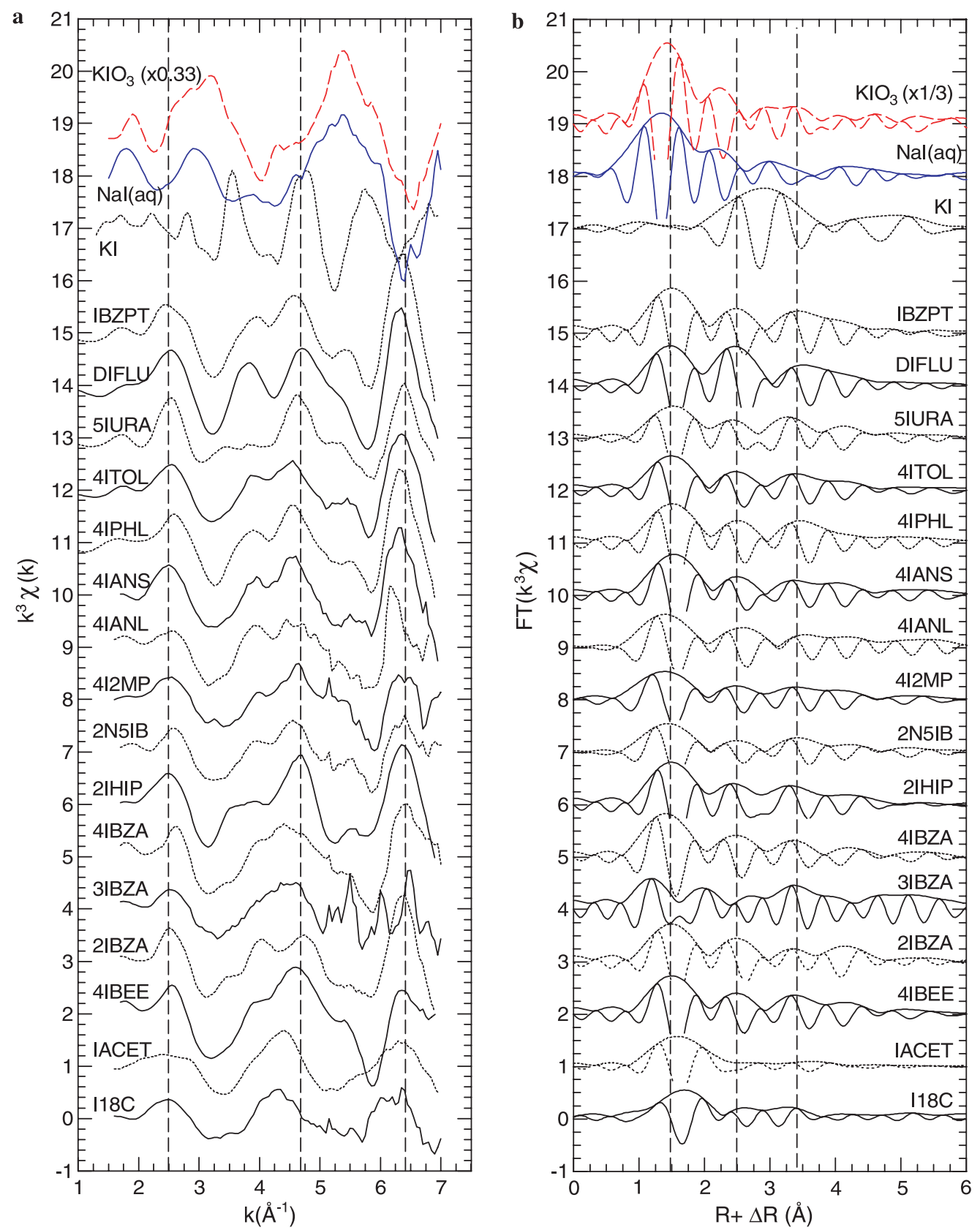

Fig. 3. (a) Iodine $\mathrm{L}_{3}$-edge EXAFS spectra for inorganic and organic compounds. (b) Comparison of selected Fourier transforms (FTs) for iodine in inorganic and organic references.

For example, the oscillation maximum near $3.8 \AA^{-1}$ for diiodo-fluoresceine (DIFLU) is absent for 5-iodouracil (5IURA). Again, this suggests that the iodine coordination environment may be unambiguously determined in favorable cases. Likewise, comparable moduli and imaginary parts of the FTs for organic references can be noted (Fig. 3b). Specifically, a FT maximum at $R+\Delta R=1.5 \AA$ (peak P1) is observed for all organic references. Peak P1 can be attributed to the contribution from the carbon atom directly bonded to iodine at $\sim 2-2.1 \AA$, and possibly from other atoms forming an ordered shell around iodine. Because the iodine-carbon bond is covalent, the $d(\mathrm{I}-\mathrm{C})$ bond length is expected to be affected only by the nature of the carbon chain or ring (aromatic versus aliphatic), and by the nature of functional groups bonding other carbons of the organic molecules. This was confirmed by spectral fitting of peak P1 (Table 4), showing that 1.99(1) $\leqslant d(\mathrm{I}-\mathrm{C}) \leqslant 2.16(2) \AA$. Relatively large uncertainties on $d(\mathrm{I}-\mathrm{C})(\geqslant 0.02 \AA)$ and on $\Delta E_{0}$ were sometimes observed for the fits. These uncertainties can be explained by the limited $\mathrm{k}$ range available for fitting (Table 4), and by the correlation usually occurring between $d(\mathrm{I}-\mathrm{C})$ and $\Delta E_{0}$ during the fit (Teo, 1986). However, all $d(\mathrm{I}-\mathrm{C})$ for iodine bound to an aromatic ring (aromatic-bound iodine) are $\leqslant 2.08(6) \AA$, whereas, for iodine bound to aliphatic chains (aliphaticbound iodine $), d(\mathrm{I}-\mathrm{C}) \geqslant 2.15(2) \AA$. The shorter distance 
Table 4

Quantitative EXAFS analysis of the first I-C coordination shell in organic references

\begin{tabular}{|c|c|c|c|c|c|c|c|c|c|}
\hline Reference & $\Delta R^{\mathrm{a}}(\AA)$ & $\Delta k^{\mathrm{b}}\left(\AA^{-1}\right)$ & $N_{\mathrm{C}}$ & $d(\mathrm{I}-\mathrm{C})(\AA)$ & $\sigma^{2 \mathrm{c}}\left(\AA^{2}\right)$ & $\Delta E_{\mathrm{O}}^{\mathrm{d}}(\mathrm{eV})$ & $N_{\mathrm{I}}^{\mathrm{e}}$ & $N_{\text {fit }}{ }^{\mathrm{g}}$ & $R_{\mathrm{f}}^{\mathrm{h}}$ \\
\hline 2IHIP & $0.8-2.05$ & $1.7-6.65$ & $1^{\mathrm{f}}$ & $2.06(4)$ & $0.001(3)$ & $-2.3(6.1)$ & 6 & 3 & 0.002 \\
\hline $2 \mathrm{~N} 5 \mathrm{IB}$ & $0.8-2.1$ & $1.6-6.6$ & $1^{\mathrm{f}}$ & $2.04(2)$ & $0.0066(13)$ & $-4.4(2.3)$ & 6 & 3 & 0.0006 \\
\hline 2IBZA & $0.8-2.0$ & $1.6-6.8$ & $1^{\mathrm{f}}$ & $2.03(4)$ & $0.0062(24)$ & $-6.3(5.0)$ & 6 & 3 & 0.0015 \\
\hline 3IBZA & $0.8-2.05$ & $1.6-6.6$ & $1^{\mathrm{f}}$ & $2.05(16)$ & $0.011(10)$ & $-3.7(16.5)$ & 6 & 3 & 0.017 \\
\hline 4IBZA & $0.8-2.0$ & $2.1-6.95$ & $1^{\mathrm{f}}$ & $2.02(2)$ & $0.0015(9)$ & $-5.8(2.1)$ & 5 & 3 & 0.0005 \\
\hline $4 \mathrm{I} 2 \mathrm{MP}$ & $0.8-2.0$ & $1.6-6.6$ & $1^{\mathrm{f}}$ & $1.99(2)$ & $0.0060(15)$ & $-5.7(2.6)$ & 5 & 3 & 0.0005 \\
\hline 4IBEE & $0.8-2.0$ & $1.5-6.7$ & $1^{\mathrm{f}}$ & $2.02(3)$ & $0.0011(14)$ & $-5.2(3.5)$ & 6 & 3 & 0.019 \\
\hline 4IANL & $0.8-2.0$ & $1.4-6.6$ & $1^{\mathrm{f}}$ & $2.02(3)$ & $0.0033(14)$ & $-7.7(3.0)$ & 6 & 3 & 0.0005 \\
\hline 4IANS & $0.9-2.1$ & $1.5-6.6$ & $1^{\mathrm{f}}$ & $2.08(6)$ & $0.0013(32)$ & $-0.6(5.9)$ & 6 & 3 & 0.0026 \\
\hline 4IPHL & $0.9-2.1$ & $1.5-6.7$ & $1^{\mathrm{f}}$ & $2.05(5)$ & $0.0022(30)$ & $-2.4(5.3)$ & 6 & 3 & 0.008 \\
\hline 4ITOL & $0.8-2.05$ & $1.5-6.7$ & $1^{\mathrm{f}}$ & $2.07(6)$ & $0.0044(33)$ & $-2.6(6.1)$ & 6 & 3 & 0.0046 \\
\hline 5IURA & $0.8-2.05$ & $1.8-7.7$ & $1^{\mathrm{f}}$ & $2.04(15)$ & $0.0066(91)$ & $0.4(16.2)$ & 6 & 3 & 0.017 \\
\hline DIFLU & $0.8-2.0$ & $1.8-7.7$ & $1^{\mathrm{f}}$ & $2.02(2)$ & $0.0023(71)$ & $-5.6(5.6)$ & 6 & 3 & 0.0071 \\
\hline $1 \mathrm{II} 18 \mathrm{C}$ & $0.9-2.2$ & $1.54-6.6$ & $1^{\mathrm{f}}$ & $2.15(2)$ & $0.0094(14)$ & $3.7(1.8)$ & 6 & 3 & 0.0010 \\
\hline IACET & $0.9-2.3$ & $1.8-6.7$ & $1^{\mathrm{f}}$ & $2.16(2)$ & $0.0054(16)$ & $5.1(2.1)$ & 6 & 3 & 0.0019 \\
\hline IBZPT & $0.8-2.05$ & $1.6-6.7$ & $1^{\mathrm{f}}$ & $2.06(6)$ & $0.0005(29)$ & $-2.4(6.6)$ & 6 & 3 & 0.0026 \\
\hline \multicolumn{10}{|c|}{${ }^{\mathrm{a}}$ Range of the inverse Fourier transform. } \\
\hline \\
\hline \multicolumn{10}{|c|}{${ }^{\mathrm{c}}$ Debye-Waller factor. Some low values reported here may be explained by the low value of the upper $k$-range for the fit (Teo, 1986). } \\
\hline \multicolumn{10}{|c|}{ d Correction for the threshold energy. } \\
\hline \multicolumn{10}{|c|}{ e Number of independent parameters for the fit, calculated as $N_{\mathrm{I}}=(2 \times \Delta R \cdot \Delta k) / \pi+2($ Stern, 1993). } \\
\hline \multicolumn{10}{|c|}{${ }^{\mathrm{f}}$ Value held fixed during the fit. } \\
\hline \multicolumn{10}{|c|}{ g Number of fitting parameters. Note that $N_{\text {free }}$ is always smaller than $N_{\mathrm{I}}$. } \\
\hline
\end{tabular}

for aromatic-bound iodine can be easily accounted for by the stronger bond strength in these compounds, due to the presence of resonnant $\pi$ bonding orbitals.

Two additional peaks at 2.5 (peak P2) and $3.4 \AA$ (peak P3) were also detected for aromatic-bound iodine (Fig. 3b). A topological analysis indicated that peak P2 can be related to contributions from a second carbon shell at $\sim 3.0 \AA$, coinciding with the two next-nearest (ortho) carbons of the ring, and peak $\mathrm{P} 3$ to contributions from atomic shells near $4 \AA$, possibly from meta carbons of the ring. Because of atomic packing in solids, peaks P2 and P3 may also include other intra- and intermolecular contributions, and multiple-scattering contributions within the aromatic ring. Therefore, the amplitude of peaks P2 and P3 may be altered by interference effects from these additional contributions. However, examination of Fig. 3b shows that slight modifications in amplitude and positions of peak P2 and P3 for aromatic-bound iodine are observed. This may result from the fact that multiple-scattering contributions are comparable for all aromatic-bound iodine, whereas atomic shells at $>3.1 \AA$ consist mostly of light elements $(\mathrm{H}, \mathrm{C}, \mathrm{N}, \mathrm{O})$ in disordered shells, thus leading to weak EXAFS contributions. Note that peaks P2 and P3 are absent in the FT for IACET and significantly shifted in position in 1-iodo-octodecane (1I18C) relatively to aromatic-bound iodine. The presence and position of these peaks may therefore be used to trace binding between iodine and aromatic rings.

A greater disparity in the distance and amplitude of nearest neighbors can be observed for the inorganic compounds (Fig. 3b). The presence of two FT peaks near 1.3 and $2.3 \AA$ for $\mathrm{KIO}_{3}$ is consistent with the presence of two shells of three oxygens each at 1.8 and $2.7 \AA$, forming a distorted coordination octahedron (Lucas, 1984). Likewise, the first FT peak near $2.8 \AA$ for KI may be related to a $\mathrm{K}$ backscattering shell near $3.2 \AA$. The position and imaginary parts of the first FT peaks for (hydr) NaI parallel those obtained for $\mathrm{KIO}_{3}$, suggesting that iodine in the hydrated salt is predominately bound by oxygen molecules. Interestingly, the imaginary parts of the first peaks are outof phase with those of peak P1 in organic references (Fig. 3b). Also, the magnitude of the first FT peak for $\mathrm{KIO}_{3}$ is appreciably greater than that of peak $\mathrm{A}$ in organic compounds. This dramatic difference in amplitude may be explained by a combination of structural differences, such as the number of neighboring atoms (three oxygens in the iodine salt, versus one carbon in the organic molecules), the atomic numbers of the backscatterers $(Z=6$ for carbon, $Z=8$ for oxygen) and their distance to iodine (mean $\langle d(\mathrm{I}-\mathrm{O})\rangle \sim 1.81 \AA$ in $\mathrm{KIO}_{3}, d(\mathrm{I}-\mathrm{C}) \geqslant 1.99 \AA$ in the organic references).

In conclusion, analysis of X-ray absorption spectra for reference compounds suggests that the presence of iodine-carbon bonds could be detected by XANES and EXAFS analysis. It further suggests that XANES, EXAFS spectra and FT display distinct patterns that could be used as a fingerprint of the iodine molecular environment in favorable cases.

\subsection{X-ray absorption spectroscopy of NIHS}

\subsubsection{X-ray absorption near-edge structure}

The absorption edge of XANES spectra for NIHS are located between 4652.10(11) and 4563.08(16) eV (Fig. 4 


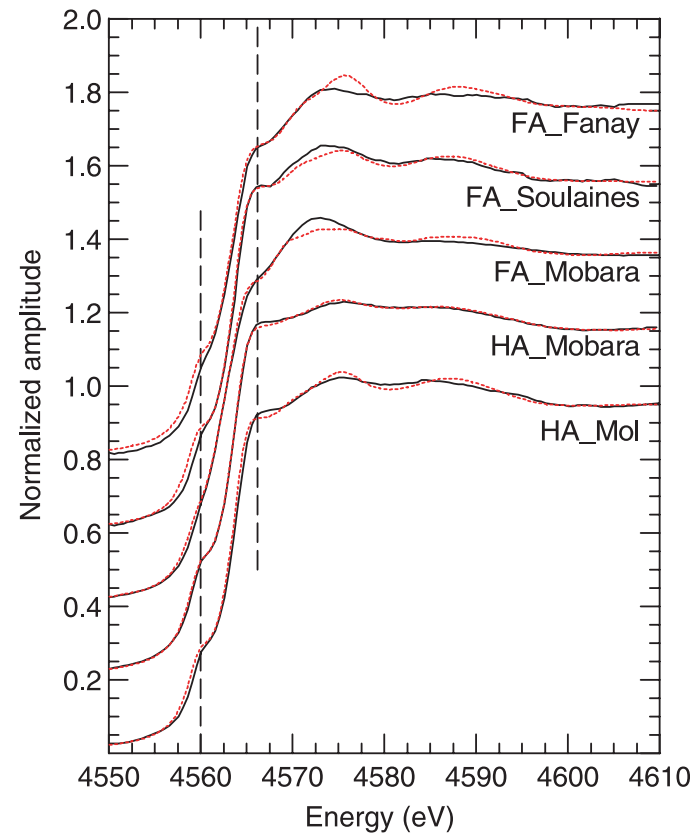

Fig. 4. (a) Iodine $\mathrm{L}_{3}$-edge XANES spectra for iodine in natural organic matter. Solid line: experimental spectra. Dotted lines: linear combination of XANES spectra from reference compounds to reproduce the experimental spectra.

and Table 5). These energies compare to those of organic references, suggesting that XANES spectra for the probed NIHS are dominated by contributions from carbon-bound iodine. Another clue to the existence of iodine covalent bonds is the presence of an absorption shoulder near $4560 \mathrm{eV}$ for all samples, as for the organic references. Finally, additional shoulders and bands are observed near 4566,4574 , and $4585 \mathrm{eV}$, i.e., within the range of the respective $\mathrm{C}, \mathrm{D}-\mathrm{E}$, and $\mathrm{F}$ absorption bands of the organic references (Tables 3 and 5). However, no exact coincidence in peak position between the references and the samples could be found. This suggests that iodine binds either to a functional group which has no equivalent among the references, or more likely to several distinct groups. Interestingly, the XANES spectra for HA_Mobara and FA_Mobara differ from each other in amplitudes of the edge shoulder, as well as in positions of the post-edge absorption bands (Fig. 4). These dissimilarities indicate that iodine either binds to distinct types of organic molecules, or to contrasted proportions of several $(\geqslant 2)$ organic molecules, in the two fractions. Therefore, at least two distinct coordination environments must be present to explain the XANES spectral discrepancies for NIHS according to their origin.

The XANES spectra average the contributions of iodine located in distinct molecular environments. Consequently, the iodine chemical speciation in NIHS were tentatively estimated by reproducing the sample spectra with a linear combination of structural references, a procedure successfully applied to sulfur (see, e.g., Sarret et al., 2002). This should be seen as an exercise since the database of iodine reference compounds used in this study is not exhaustive. The quality of the XANES normalization can be appreciated by noting that for all best-fit simulations, the sum of the fractional coefficients $X_{j}$ affected to the model compounds was within the $[0.99,1.01]$ range. Fig. 4 shows that the edge positions were generally well modeled for all samples by assuming a predominance of organic compounds, as anticipated from the edge spectral features. In contrast, the post-edge features, were not so well modeled, leading, in some cases, to clear discrepancies in the position and amplitudes of XANES bands, as evident, e.g., for FA_Fanay. This fit discrepancy cannot be explained by normalization issues, and therefore it may result from the absence, in the database, of compounds with XANES signatures comparables to those of iodine in NIHS. In fact, in a study of bromine in solids and solution, Matsuo et al. (2003) showed that some XANES bands observed at the bromine $\mathrm{L}_{3}$-edge in solid salts disappear when bromine was dissolved in an aqueous, disordered environment. By analogy with bromine, iodine in chemically heterogeneous, and permeable media like HS (Engebretson and von Wandruszka, 1994; Duval et al., 2005) may be present in a disordered environment that is comparable to that of dissolved elements, and structurally distinct from the crystalline-like environment in solid references. This disordered environment would result in relatively damped oscillations in XANES spectra, just like the 5IURA spectrum. Interestingly, the fit for FA_Soulaines $\left(R_{\mathrm{f} 1}=1.9 \times 10^{-4}\right)$ yielded a combination of $59 \%$ (molar) 5IURA, 27\% IACET, 9\% 4-iodo,2-methyl phenol (4I2MP) and 3\% $\mathrm{KIO}_{3}$. Assuming that iodine is actually coordinated to $59 \%$ of 5IURA $\left(\mathrm{C}_{4} \mathrm{~N}_{2} \mathrm{O}_{2} \mathrm{H}_{3} \mathrm{I}\right)$ would imply that a minimum of $0.7 \%$ of the FA mass is made up by nitrogen. This amount is hardly smaller than the total amount of nitrogen in FA_Soulaines (Table 1), and the resulting speciation (more than $50 \%$ of

Table 5

Energy position (in $\mathrm{eV}$ ) of main iodine $\mathrm{L}_{3}$-edge shoulders and peaks on XANES spectra for inorganic and organic reference compounds

\begin{tabular}{lllll}
\hline Sample-origin & Edge energy & $\mathrm{A}^{\mathrm{s}}$ & $\mathrm{C}$ & $\mathrm{E}$ \\
\hline Fulvic acid-Fanay & $4562.9(2)$ & 4560.5 & $4566.5^{\mathrm{s}}$ & 4574 \\
Fulvic acid-Soulaines & $4562.86(15)$ & 4560.5 & 4566.5 & 4573.5 \\
Fulvic acid-Mobara & $4562.10(11)$ & 4560.5 & $4566.5^{\mathrm{s}}$ & 4586.5 \\
Humic acid-Mobara & $4562.66(3)$ & 4560.5 & $4566.5^{\mathrm{s}}$ & 4585.5 \\
Humic acid-Mol & $4563.08(16)$ & 4560.5 & $4566.5^{\mathrm{s}}$ & 4575.5 \\
\hline
\end{tabular}

Except when explicitly reported, all uncertainties are $\pm 0.5 \mathrm{eV}$.

${ }^{s}$ Absorption feature appearing as a shoulder. 
nitrogen in aromatic rings) seems to contradict previous results showing the predominance $(\sim 70-80 \%)$ of amide compounds in humic substances (Vairavamurthy and Wang, 2002).

With all these limitations in mind, it becomes clear that the decomposition cannot be interpreted as indicative of an exact speciation. Rather, it should be taken as suggestive of the general trends in iodine speciation. For example, the fit $\left(R_{\mathrm{f}}=1.9 \times 10^{-5}\right)$ obtained for HA_Mobara $(51 \%$ 3IBZA, $27 \%$ 2-iodohippuric acid (2IHIPU), and 22\% IACET) supports iodine coordination to mostly aromatic rings, and, perhaps, some aliphatic chains. Likewise, the fits to FA_Fanay (49\% of 4-iodoaniline (4IANL), 35\% 5IURA, and $15 \%$ of $\mathrm{KIO}_{3} ; R_{\mathrm{f} 1}=3.8 \times 10^{-4}$ ), FA_Soulaines $\left(60 \%\right.$ 5IURA, $27 \%$ IACET, $30 \% \mathrm{KI}$, and $3 \% \mathrm{KIO}_{3}$; $\left.R_{\mathrm{f} 1}=1.4 \times 10^{-4}\right)$ and HA_Mol $(44 \%$ 5IURA, 36\% 3IHIPU, $14 \%$ IIANL, and $5 \% \mathrm{KIO}_{3} ; R_{\mathrm{fl}}=1.7 \times 10^{-4}$ ) all point to iodine binding to a complex mixture of aromatic moieties in a disordered environment. Finally, the inclusion of some KI in the fit for FA_Mobara accounts for the weakness of the shoulder near $4560 \mathrm{eV}$, and for the rather low edge energy. This result supports the presence of iodide in FA_Mobara. Whether this iodide is electrostatically bound to charged sites of the organic matter (e.g., charged nitrogen sites) or salted out during the sample purification or lyophilization, could not be clarified from this analysis.

\subsubsection{Extended $X$-ray absorption fine structure}

Due to the relatively low iodine content of most samples, EXAFS spectra over a significant $\delta k$ range could be recorded only for FA_Mobara, HA_Mobara, and HA_Mol. These $k^{3} \chi(k)$ spectra resemble those of organic references (Fig. 5a). Specifically, comparable oscillation maxima near $2.5,4.6$, and $6.5 \AA^{-1}$ could be observed for organic references and the NIHS, suggesting some similarities in the EXAFS contributions. This inference is further confirmed by the coincidence in position and imaginary parts of the FT peaks $\mathrm{P} 1, \mathrm{P} 2$, and $\mathrm{P} 3$ for the HA samples and for aromatic-bound iodine references (Fig. 5b). For FA_Mobara, however, the first and second peaks are located at lower and higher $R+\Delta R$ values, and the amplitude of peak P1 is significantly lower (by $\sim 50 \%$ ) than for the aromatic-bound iodine references. These dissimilarities can be explained by iodine located in several distinct environments, and/or surrounded by disordered first shells, in agreement with the results of XANES decomposition suggesting the presence of iodide. Also, a decrease in amplitude of P1 may result from the cancellation of EXAFS waves backscattered by carbon and by oxygen atoms (e.g., water molecules, hydroxyl ions, or carboxylic groups) that may surround some iodine atoms.

The iodine molecular properties in NIHS was further investigated by Fourier-filtering and fitting peak P1. As for the organic references, good fits were obtained assuming a carbon contribution, with a number of carbon neighbors $\left(N_{\mathrm{C}}\right)$ usually close to one, and $d(\mathrm{I}-\mathrm{C})$ distances spanning the $[2.01,2.04 \AA]$ interval (Table 6), in excellent agreement
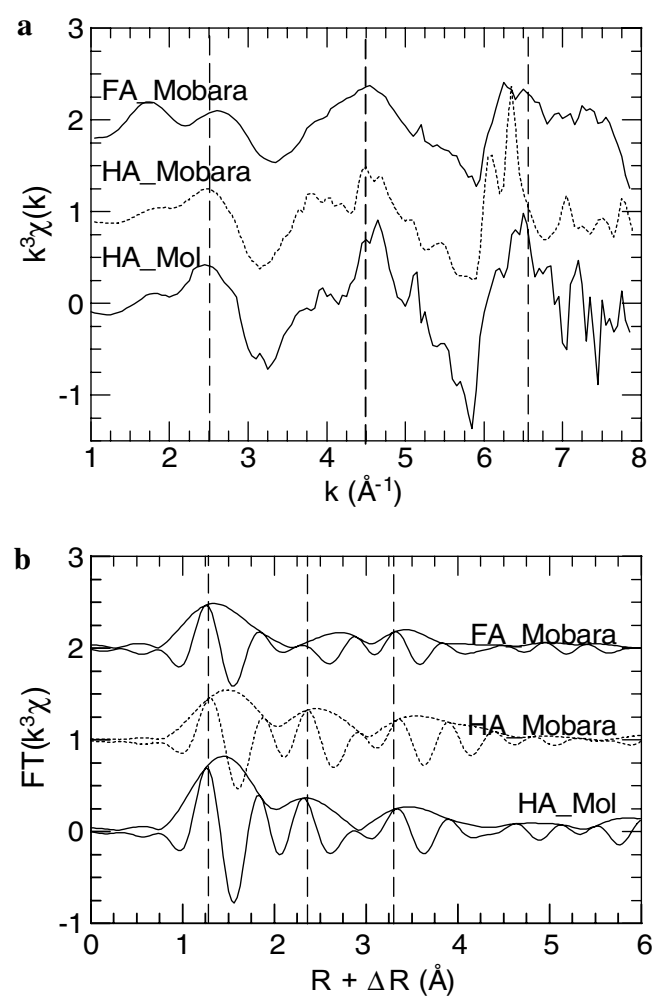

Fig. 5. (a) Iodine $\mathrm{L}_{3}$-edge $k^{3}$-weighed EXAFS spectra for iodine in natural organic matter. (b) FT moduli and imaginary parts for iodine in NIHS.

with $d(\mathrm{I}-\mathrm{C})$ values for aromatic references (Table 4). Note that carbon and nitrogen have comparable covalent radii, and therefore the presence of a major proportion of iodoamines would have resulted in an apparent $d(\mathrm{I}-\mathrm{N})$ bond of $\sim 2.15 \AA$. Tentative fitting leads to short $d(\mathrm{I}-\mathrm{N})(\leqslant 2.06 \AA)$, and so this hypothesis could be dismissed.

\section{Discussion}

Three major results may be drawn from the NIHS spectroscopic investigation. First, most iodine is covalently bound to NOM. Second, in each sample, iodine is probably bound to more than one type of molecule. Third, from simulation of XANES spectra, and from the EXAFS analysis of FA_Mobara, HA_Mobara and HA_Mol, aromaticbound iodine predominates. Note that this binding to aromatic rings appears as an invariant, regardless of the variety in origin of the NIHS. Also, decompositions of XANES spectra reveal the presence of iodide in only one sample, i.e., FA_Mobara.

The NIHS probed in this study were previously investigated by XPS (Mercier et al., 2000, 2001, 2002). The values for the $\mathrm{I}_{3 \mathrm{~d} 5 / 2}$ binding energy obtained for NIHS were close to those observed for organic references $(620.5-621.5 \mathrm{eV})$, suggesting that the bonds between iodine and NIHS molecules are not of ionic nature but rather of covalent character. This was corroborated by the shape of the XPS band showing that only one major contribution predominated 
Table 6

Quantitative EXAFS analysis of the first I-C coordination shell in NIHS

\begin{tabular}{|c|c|c|c|c|c|c|c|c|c|}
\hline Sample & $\Delta R^{\mathrm{a}}(\AA)$ & $\Delta k^{\mathrm{b}}\left(\AA^{-1}\right)$ & $N_{\mathrm{C}}$ & $d(\mathrm{I}-\mathrm{C})(\AA)$ & $\sigma^{2 \mathrm{c}}\left(\AA^{2}\right)$ & $\Delta E_{\mathrm{O}}^{\mathrm{d}}(\mathrm{eV})$ & $N_{\mathrm{I}}^{\mathrm{e}}$ & $N_{\text {fit }^{\mathrm{g}}}^{\mathrm{g}}$ & $R_{\mathrm{f}}^{\mathrm{h}}$ \\
\hline FA_Mobara & $0.8-2.2$ & $1.4-6.8$ & $0.7(1)$ & $2.01(3)$ & $0.004^{\mathrm{f}}$ & $-6.8(3.4)$ & 6 & 3 & 0.008 \\
\hline HA_Mobara & $0.8-2.0$ & $1.5-6.6$ & $0.8(3)$ & $2.04(9)$ & $0.004^{\mathrm{f}}$ & $-5.7(10.2)$ & 6 & 3 & 0.005 \\
\hline HA_Mol & $0.8-2.0$ & $1.5-6.9$ & $1.1(2)$ & $2.01(4)$ & $0.004^{\mathrm{f}}$ & $-5.8(5.2)$ & 6 & 3 & 0.004 \\
\hline
\end{tabular}

${ }^{a}$ Range of the inverse Fourier transform.

b $k$-range of the fit.

${ }^{c}$ Debye-Waller factor.

d Correction for the threshold energy.

${ }^{\text {e }}$ Number of independent parameters for the fit, calculated as $N_{\mathrm{I}}=(2 \times \Delta R \cdot \Delta k) / \pi+2$ (Stern, 1993).

${ }^{\mathrm{f}}$ Value held fixed during the fit.

g Number of fitting parameters. Note that $N_{\text {free }}$ is always smaller than $N_{\mathrm{I}}$.

${ }^{\mathrm{h}}$ Measure of the fit quality.

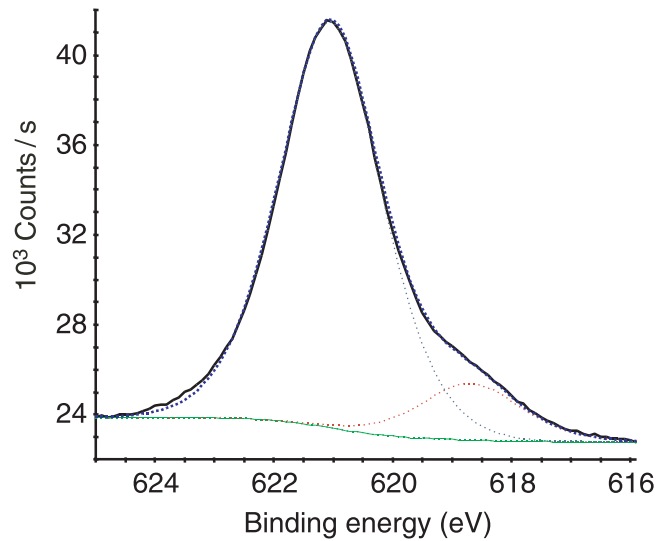

Fig. 6. X-ray photoelectron spectrum of iodine in the HA_Mobara sample. The dotted line represents the experimental $\mathrm{I}_{3 \mathrm{~d} 5 / 2}$ spectrum (Mercier et al., 2002) and the straight line corresponds to the spectral decomposition with the software AVANTAGE. The decomposition yields two components at $621.1 \mathrm{eV}$ and $618.7 \mathrm{eV}$.

near $\sim 621 \mathrm{eV}$, except for FA_Mobara (Mercier et al., 2002), for which a low-energy shoulder suggestive of reduced iodine was also observed (Fig. 6). This inference was confirmed by a decomposition of the $\mathrm{I}_{3 \mathrm{~d} 5 / 2}$ peak for FA_Mobara, revealing a major XPS contribution at $621.1 \mathrm{eV}$, with a minor contribution at $618.7 \mathrm{eV}$. This low-energy component can be unambiguously attributed to iodide. Note that the presence of iodide was surmised from the simulations of XANES spectra. This suggests that these simulations, albeit still limited in their ability to fully provide a speciation of organic iodine, can supply useful information on the presence of reduced iodine in samples.

Our EXAFS spectral results also compare very well with the detection of iodine covalent bonds by ESI-MS (Moulin et al., 2001). Both techniques reveal the predominant interaction of iodine with aromatic rings. Because of its sensitivity to mass properties of the iodinated molecules, ESI-MS can in addition provide some information on the nature of functional groups attached to the iodinated aromatic rings. This molecular speciation in "laboratory-iodinated HS" is compatible with the iodine molecular environment in the field. However, it is unclear whether this coincidence implies that iodination mechanisms were comparable in the laboratory and in the field.

\subsection{Possible limitations on the spectroscopic results of iodine speciation}

Extrapolation of the result from XPS and XAS analysis to natural organic matter in soils and aquifers might be hampered by two possible limitations. First, spectroscopic data were collected on purified HS extracted on columns, and contacted several times with acid/base solutions. As often pointed out previously, procedures of NOM purification can lead to artifactual formation of new molecules and changes in the organic speciation, through hydrolysis of chemical bonds, and rearrangement of the known structure (Kumke et al., 2001; Myneni, 2002a; Vairavamurthy and Wang, 2002). In our case, only mild treatments were used, and harsh treatments, such as dissolution of the inorganic fraction by hydrofluoric acid, or NOM conservation in base solutions, were avoided. Therefore these artifacts were limited. Also, NIHS were dried by lyophilization, and this procedure likely removed all compounds that could evaporate or sublimate under vacuum conditions, such as iodoalkanes. In fact, this lyophilization may benefit XPS, for which evaporation of volatile compounds in the XPS chamber can delay the onset of ultra-high vacuum conditions. An alternate procedure of NIHS concentration without drying might be applied for XAS, which has no such volatility limitation. However, in this case analysis of dilute samples may be limited by the overall low solubility of humic substances.

Second, the linear decomposition of XANES in terms of individual species is necessarily limited by the extent and variety of the reference database. As explained previously, the relatively ordered chemical environment of iodine in pure solids may be significantly distinct from that in heterogeneous aggregates. Furthermore, XAS probes a volume of space, up to $7 \AA$, around the target atom, and so, even if iodine binds to a functional group that is well represented in the database, other neighboring molecules may greatly differ from this particular functional group. Therefore, the number of possible molecular environments for iodine would hardly be matched by any reference collection. Taking these limitations into account, the XANES simulations by linear combination of reference spectra have to be taken with great care. 


\subsection{Mechanism of iodine retention by natural organic matter}

The short $d(\mathrm{I}-\mathrm{C})$ distances observed in all samples, and the presence of next-nearest neighboring $\mathrm{P} 2$ and perhaps P3 contributions are evidence for the prevalence of aromatic-bound iodine in agreement with the structure determined by ESI-MS (Moulin et al., 2001). The iodine binding to aromatic rings may not be explained by reoxidation of dissolved iodide and subsequent reaction with organic matter, as iodide is known to be unreactive with NOM on the timescale of months when stabilized, unless it is oxidized to $v_{\mathrm{I}} \geqslant 0$ (Reiller and Moulin, 2003). Taking into account the known reductive properties of humic substances, this oxidation is not likely to be mediated by HS themselves (Österberg and Shirshova, 1997). The two possible mechanisms that may lead to an iodine fixation to aromatic entities of HS are either the slow oxidation of iodide to iodine (Wong, 1991) as it may happen in the works of Mercier et al. (2000), or iodine oxidation by an enzymatic reaction, but in natural systems (Wagenknecht and Woggon, 1997). Ashworth et al. (2003) and Bostock et al. (2003) clearly showed that iodine accumulates in soil at the redox interface at some tenth of centimeter below the surface associated with NOM and particularly to humic substances. This accumulation was also observed by Kashparov et al. (2005), but the correlation with iodine content of humic substances was not verified experimentally.

This result confirms that the short-term iodination of aromatic rings surmised from laboratory experiments (Warner et al., 2000) and observed by ESI-MS (Moulin et al., 2001) prevails over long periods of time. In fact, datation of HA_Mol performed by measuring the residual ${ }^{14} \mathrm{C}$ by mass spectrometry yielded an age of $1.4 \times 10^{4}$ years (Montjotin, 1996). For Mobara, datation of iodine by evaluation of the decay of pre-anthropogenic ${ }^{129}$ I gave an age of $\sim 5 \times 10^{7}$ years (Muramatsu et al., 2001). Therefore, stable association between iodine and NIHS over long timescales seems valid for an important range of iodine to NOM ratios. The contrast in iodine to NOM ratios may result from iodination of HS in surface environments with distinct iodine concentrations (Sheppard et al., 1995). Alternatively, they may reflect in situ rates of iodination, e.g., by $\mathrm{I}_{2} / \mathrm{HIO}$ in equilibrium with $\mathrm{I}^{-}$. Such a reaction may eventually lead to significant iodination, owing to the extremely long contact time between iodine and organic matter (centuries, i.e., six to seven orders of magnitude longer than laboratory experiments) and the near-neutral $\mathrm{pH}$ conditions favoring this reaction (Lee, 1967; Bichsel and von Gunten, 2000).

The amount of iodine that can possibly fix to NIHS by covalent aromatic bonds can be evaluated from the amount of phenolic groups in the organic matter. Warner et al. (2000) reported that the amount of phenolic acidity (a crude estimate of the amount of phenolic group) in their investigated organic matter is quite elevated, ranging between $0.2 \pm 0.06$ and $6.5 \pm 3.5 \mathrm{~mol} \mathrm{~kg}^{-1}$. Assuming one io- dine atom would bind to each phenolic ring, a maximum content in iodine up to $50 \mathrm{wt} \%$ could be expected in the most favorable case. Our maximum content in iodine is $10 \mathrm{wt} \%$, which compares fairly well with these saturation values. Interestingly, the two best tentative fits of XANES spectra (FA_Soulaines and HA_Mobara) both yield a significant fraction of references in which iodine binds to polysubstituted rings.

\subsection{Implication for iodine speciation and migration in the environment}

Aromatic-bound iodine is quite stable, as it may only be substituted by a stronger electrophile, and therefore little release of inorganic iodine can be anticipated. Possible decomposition of the iodine covalent bond to aliphatic chains may occur by nucleophiles such as dissolved sulfides or thiosulfates. Indeed, pyrite is a ubiquitous components in reduced sedimentary environments such as the Mol formation (Bruggeman et al., 2005), and its oxidative dissolution may release thiosulfates in solution, but only at acidic $\mathrm{pH}$ (Descostes et al., 2004). To our opinion, these reactions are not likely to occur in $\mathrm{pH}$-buffered sedimentary formations.

In other natural systems, it has been shown that halogens in general and iodine in particular are fixed to NOM when a redox interface between oxidant and reductive medium exists (Ashworth et al., 2003). It is also known that enzymatic reactions can promote electrophilic substitution on phenolic moieties by halogens from an halogenide form (Wagenknecht and Woggon, 1997). Once this covalent bond is formed, the stability of the organoiodine compounds solely depends on the presence of strong electrophilic substituents, as in the abiotic case.

That aromatic-bound iodine predominates in NIHS has significant implication for the radiotoxicity or long-term behavior of radioiodine in soils and aquatic environments. For example, experiments of iodine transport in soil columns demonstrated that iodide, iodate, and organic iodine as 4IANL each displayed unique breakthrough patterns, with increasing transport delays (Hu et al., 2005). The diffusion coefficient for 4IANL was found to be one order of magnitude lower than for iodide. Hu et al. (2005) suggested that the transport delay of iodate and 4IANL could result from interaction between these iodine species and immobile organic macromolecules. Additional experiments of iodide transport in clay samples have also revealed some transport delay (Bazer-Bachi, 2005; Bazer-Bachi et al., 2006). This delay may result from conversion of some iodide to diiodine $\left(\mathrm{I}_{2}(\mathrm{aq})\right)$ in thermodynamic equilibrium, followed by covalent binding of iodine to organic matter. Because a major proportion of iodine can bind to humic substances (from $40 \%$ up to $90 \%$ in Dannish groundwaters; Andersen et al., 2002), and from $45 \%$ to $\sim 100 \%$ in soils (Sheppard and Thibault, 1992; Yamada et al., 1999), the long-term mobility of (organic) iodine in terrestrial waters should eventually compare with that of NOM such as HA of FA. 
In conclusion, iodine bound to NIHS is mostly attached to aromatic rings. This chemical binding is rather stable over long time scales in deep aquifers. Thus the iodine fate in aquifers and soils would chiefly depend on the behavior of this NOM. Insoluble and mineral-adsorbed NOM may act as an iodine trap (Andersen et al., 2002). However, the amount of iodine bound to insoluble humin in soils represents only a minor fraction compared to FA and HA (Sheppard and Thibault, 1992; Sheppard et al., 1995), suggesting that the reactivity of these insoluble fractions do not scale compared to that of dissolved NOM. In this latter fraction, organic molecules are expected to act as an iodine carrier in the environment in a molecular form, instead of the anionic one. Most likely, migration of this organically bound iodine is retarded with respect to inorganic iodine (Hu et al., 2005).

Interestingly, this long-term mechanism of iodine retention by NIHS parallels the long-term mechanism of chlorine retention in weathering plant materials (Myneni, 2002b; Reina et al., 2004). Based on soft XAS, it was demonstrated that humification shifted the chlorine speciation from mostly aliphatic-bound chlorine to mostly aromaticbound chlorine. Thus, it may be anticipated that bromine, intermediate halogen between iodine and chlorine, will react similarly.

\section{Acknowledgments}

Laurent Alvarez and Christophe den Auwer are acknowledged for their technical assistance on ID26 and D44, respectively. We thank ESRF and Lure for provision of beamtime. Dr. Jay Brandes and two anonymous reviewers are thanked for their insightful and constructive comments on this manuscript.

Associate editor: Jay A. Brandes

\section{Appendix A. Supplementary material}

Supplementary data associated with this article can be found, in the online version, at doi:10.1016/ j.gca.2006.08.026.

\section{References}

Aberdam, D., 1998. SEDEM, a software package for EXAFS data extraction and modelling. J. Synchrotron Radiat. 5, 1287-1297.

Andersen, S., Petersen, S.B., Laurberg, P., 2002. Iodine in drinking water in Denmark is bound in humic substances. Eur. J. Endocrinol. 147, 663-670.

Ankudinov, A.L., Rehr, J.J., 1997. Relativistic calculations of spin-dependent x-ray absorption spectra. Phys. Rev. B 56, 1712-1715.

Ashworth, D.J., Shaw, G., Butler, A.P., Ciciani, L., 2003. Soil transport and plant uptake of radio-iodine from near-surface groundwater. $J$. Environ. Radioact. 70, 99-114.

Atkins, P.W., 1994. Physical Chemistry, fifth ed. Oxford university press, Oxford.
Bazer-Bachi, F., 2005. Etude de l'influence de la rétention chimique sur la diffusion d'espèces anioniques dans les milieux argileux compacts. Ph.D. thesis, Institut National Polytechnique de Lorraine, Nancy, France.

Bazer-Bachi, F., Tevissen, E., Descostes, M., Grenut, B., Meier, P., Simonnot, M.-O., Sardin, M., 2006. Characterization of iodide retention on Callovo-Oxfordian argillites and its influence on iodide migration. Phys. Chem. Earth 31, 517-522.

Bichsel, Y., von Gunten, U., 1999. Oxidation of iodide and hypoiodous acid in the disinfection of natural waters. Environ. Sci. Technol. 33, 4040-4045.

Bichsel, Y., von Gunten, U., 2000. Formation of iodo-trihalomethanes during disinfection and oxidation of iodide containing waters. Environ. Sci. Technol. 34, 2784-2791.

Bors, J., Martens, R., Kuhn, W., 1988. Studies on the role of natural and anthropogenic organic substances in the mobility of radioiodine in soils. Radiochim. Acta 44/45, 201-206.

Bostock, A.C., Shaw, G., Bell, J.N.B., 2003. The volatilisation and sorption of ${ }^{129} \mathrm{I}$ in coniferous forest, grassland and frozen soils. $J$. Environ. Radioact. 70, 29-42.

Brezonik, P.L., 1994. Chemical Kinetics and Process Dynamics in Aquatic Systems. Lewis, Boca Raton, FL.

Brown Jr., G.E., Calas, G., Waychunas, G.A., Petiau, J., 1988. X-ray absorption spectroscopy: applications in mineralogy and geochemistry. In: Hawthorne, F.C. (Ed.), Spectroscopic Methods in Mineralogy and Geochemistry. Reviews in Mineralogy, vol. 18. Mineralogical Society of America, Washington, DC, pp. 431-512.

Bruggeman, C., Maes, A., Vancluysen, J., Vandenmussele, P., 2005. Selenite reduction in Boom clay: effect of $\mathrm{FeS}_{2}$, clay minerals and dissolved organic matter. Environ. Pollut. 137, 209-221.

Chagué-Goff, C., Fyfe, W.S., 1996. Geochemical and petrographical characteristics of a domed bog, Nova Scotia: a modern analogue for temperate coal deposits. Org. Geochem. 24, 141-158.

Cooksey, R.C., 1985. Humic substances, a possible source of environmental goitrogens. Org. Geochem. 8, 77-80.

Damodharan, L., Pattabhi, V., Behera, M., Kotha, S., 2003. Ethyl 2formamido-2-(4-iodobenzyl)-3-(4-iodophenyl)propionate and ethyl 2(3-bromobenzyl)-3-(3-bromophenyl)-2-formamidopropionate. Acta Crystallogr. C59, O216-O218.

Dellis, T., Moulin, V., 1989. Isolation and characterization of natural colloids, particularly humic substances, present in a groundwater. In: Miles, E. (Ed.), Proceedings of the 6th International Symposium on Water-Rock Interaction. Malvern/Balkema, Rotterdam, pp. 197-201.

Descostes, M., Vitorge, P., Beaucaire, C., 2004. Pyrite dissolution in acidic media. Geochim. Cosmochim. Acta 68, 4559-4569.

Devell, L., Tovedal, H., Bergström, U., Appelgren, A., Chyssler, J., Andersson, L., 1986. Initials observations of fallout from the reactor accident at Chernobyl. Nature 321, 192-193.

Dierckx, A., Hall, A., De Canniere, P., Warwick, P., Put, M., 1998. Stability of ${ }^{125} \mathrm{I}$ and ${ }^{14} \mathrm{C}$ labelled boom clay organic matter. Radiochim. Acta 82, 379-384.

Duval, J.F.L., Wilkinson, K.J., van Leeuwen, H.P., Buffle, J., 2005. Humic substances are soft and permeable: evidence from their electrophoretic mobilities. Environ. Sci. Technol. 39, 6435-6445.

Engebretson, R., von Wandruszka, R., 1994. Microorganization in dissolved humic acids. Environ. Sci. Technol. 28, 1934-1941.

Francois, R., 1987. The influence of humic substances on the geochemistry of iodine in near-shore and hemipelagic marine sediments. Geochim. Cosmochim. Acta 51, 2417-2427.

Frechou, C., Calmet, D., 2003. ${ }^{129}$ I in the environment of the La Hague nuclear fuel reprocessing plant-from sea to land. J. Environ. Radioact. 70, 43-59.

Fuge, R., 1996. geochemistry of iodine in relation to iodine deficiency diseases. Environ. Geochem. Health 113, 201-212.

Fuhrmann, M., Bajt, S., Schoonen, M.A., 1998. Sorption of iodine on minerals investigated by X-ray absorption near-edge structure 
(XANES) and ${ }^{125} \mathrm{I}$ tracer sorption experiments. Appl. Geochem. 13, $127-141$.

Goldman, M., 1997. The Russian radiation legacy: its integrated impact and lessons. Environ. Health Perspect. 105, 1385-1391.

Guetat, P., Armand, P., Monfort, M., Fritsch, P., Flüry-Herard, A., Menetrier, F., Bion, L., Schoech, C., Masset, S., 1990. Iodes radioactifs et impacts environnemental et sanitaire-Etude bibliographique et quantification. Commissariat à l'énergie atomique, report CEA-R6065, Saclay (France).

Hou, X.L., Malencheko, A.F., Kucera, J., Dahlgaard, H., Nielsen, S.P., 2003. Iodine-129 in thyroid and urine in Ukraine and Denmark. Sci. Total Environ. 302, 63-73.

Hu, Q.H., Zhao, P.H., Moran, J.E., Seaman, J.C., 2005. Sorption and transport of iodine species in sediments from the Savannah River and Hanford Sites. J. Contam. Hydrol. 78, 185-205.

Isaure, M.-P., Laboudigue, A., Manceau, A., Sarret, G., Tiffreau, C., Trocellier, P., Lamble, G., Hazemann, J.-L., Chateigner, D., 2002. Quantitative $\mathrm{Zn}$ speciation in a contaminated dredged sediment by $\mu-$ PIXE, $\mu$-SXRF, EXAFS spectroscopy and principal component analysis. Geochim. Cosmochim. Acta 66, 1549-1567.

Johanson, K.J., 2000. Iodine in soils. Svensk Kärnbränslehantering AB (SKB), report, Stockholm (Sweden).

Kashparov, V., Colle, C., Zvarich, S., Yoschenko, V., Levchuk, S., Lundin, S., 2005. Soil-to-plant halogens transfer studies 1. Root uptake of radioiodine by plants. J. Environ. Radioact. 79, 187-204.

Krause, M.O., Oliver, J.H., 1979. Natural widths of atomic K and L levels, K $\alpha$ X-ray lines and several KLL Auger lines. J. Phys. Chem. Ref. Data 8, 329-338.

Kumke, M.U., Specht, C.H., Brinkmann, T., Frimmel, F.H., 2001. Alkaline hydrolysis of humic substances - spectroscopic and chromatographic investigations. Chemosphere 45, 1023-1031.

Lee, C.F., 1967. Kinetics of reactions between chlorine and phenolic compounds. In: Faust, S.D., Hunter, J.V. (Eds.), Principles and Applications of Water Chemistry. Wiley, New York, pp. 54-74.

Lucas, B.W., 1984. Structure (neutron) of room-temperature phase III potassium iodate, $\mathrm{KIO}_{3}$. Acta Crystallogr. C40, 1989-1992.

Lunde, G., 1929. The geochemistry of iodine and its circulation in nature. Chem. Rev. 6, 45-61.

Matishov, G.G., Matishov, D.G., Namjatov, A.E., Smith, J.N., Carroll, J., Dahle, S., 2002. Radioactivity near the sunken submarine "Kursk" in the southern Barents Sea. Environ. Sci. Technol. 36, 1919-1922.

Matsuo, S., Nashimuthu, P., Lindle, D.W., Wakita, H., Perera, R.C.C., 2003. Electronic structures of crystalline and aqueous solutions of $\mathrm{LiBr}, \mathrm{NaBr}, \mathrm{KBr}$, and $\mathrm{KBrO}_{3}$ : in situ $\mathrm{Br}$ L-edge near-edge X-ray absorption fine structure. J. Phys. Chem. B 107, 12562-12565.

Mercier, F., Moulin, V., Barre, N., Trocellier, P., Toulhoat, P., 2001. Study of a ternary system silica/humic acids/iodine: capabilities of the nuclear microprobe. Nucl. Instrum. Methods B 181, 628-633.

Mercier, F., Moulin, V., Guittet, M.J., Barre, N., Toulhoat, N., GautierSoyer, M., Toulhoat, P., 2000. Applications of NAA, PIXE and XPS for the quantification and characterization of the humic substances/ iodine association. Radiochim. Acta 88, 779-785.

Mercier, F., Moulin, V., Guittet, M.J., Barré, N., Gautier-Soyer, M., Trocellier, P., Toulhoat, P., 2002. Applications of new surface analysis techniques (NMA and XPS) to humic substances. Org. Geochem. 33, 247-255.

Montjotin, C., 1996. Isolation, caractérisation et mesure des teneurs en ${ }^{14} \mathrm{C}$ de substances humiques aquatiques: application à la datation des eaux souterraines. PhD thesis, University Paris XI, Orsay.

Moulin, V., Billon, A., Theyssier, M., Dellis, T., 1991. Study of the interactions between organic matter and transuranic elements. Commissariat à l'énergie atomique, report EUR 13651 En, Fontenay-auxRoses (France).

Moulin, V., Moulin, C., Dran, J.-C., 1996. Role of humic substances and colloids in the behavior of radiotoxic elements in relation to nuclear waste disposal. In: Gaffney, J.S., Marley, N.A., Clark, S.B. (Eds.), Humic and Fulvic Acids: Isolation, Structure, and Environmental Role, vol. 651. American Chemical Society, Washington, DC.
Moulin, V., Reiller, P., Amekraz, B., Moulin, C., 2001. Direct characterization of iodine covalently bound to fulvic acids by electrospray mass spectrometry. Rapid Commun. Mass Spectrom. 15, 2488-2496.

Muramatsu, Y., Fehn, U., Yoshida, S., 2001. Recycling of iodine in forearc areas: evidence from the iodine brines in Chiba, Japan. Earth Planet. Sci. Lett. 192, 583-593.

Myneni, S.C.B., 2002a. Soft X-ray spectroscopy and spectromicroscopy studies of organic molecules in the environment. In: Applications of Synchrotron Radiation in Low-Temperature Geochemistry and Environmental Sciences. Reviews in Mineralogy, vol. 49. Mineralogical Society of America, Washington, DC, pp. 485-579.

Myneni, S.C.B., 2002b. Formation of stable chlorinated hydrocarbons in weathering plant material. Science 295, 1039-1041.

Newville, M., 2001. IFEFFIT: interactive XAFS analysis and FEFF fitting. J. Synchrotron Rad. 8, 322-324.

Newville, M., Livins, P., Yacoby, Y., Rehr, J.J., Stern, E.A., 1993. Nearedge $\mathrm{X}$-ray absorption fine structure of $\mathrm{Pb}$ : a comparison of theory and experiment. Phys. Rev. B 47, 14126-14131.

Österberg, R., Shirshova, L., 1997. Oscillating, nonequilibrium redox properties of humic acids. Geochim. Cosmochim. Acta 61, 4599-4604.

Plancque, G., Amekraz, B., Moulin, V., Toulhoat, P., Moulin, C., 2001. Molecular structure of fulvic acids by electrospray with quadrupole time-of-flight mass spectrometry. Rapid Commun. Mass Spectrom. 15, 827-835.

Rädlinger, G., Heumann, K.G., 2000. Transformation of iodide in natural and wastewater systems by fixation on humic substances. Environ. Sci. Technol. 34, 3932-3936.

Raisbeck, G.M., Yiou, F., 1999. ${ }^{129} \mathrm{I}$ in the oceans: origins and applications. Sci. Total Environ. 238, 31-41.

Ravel, B., Newville, M., 2005. ATHENA, ARTEMIS, HEPHAESTUS: data analysis for X-ray absorption spectroscopy using IFEFFIT. $J$. Synchrotron Radiat. 12, 537-541.

Reed, W.A., May, I., Livens, F.R., Charnock, J.M., Jeapes, A.P., Gresley, M., Mitchell, R.M., Knight, P., 2002. XANES fingerprinting of iodine species in solution and speciation of iodine in spent solvent from nuclear fuel reprocessing. J. Anal. Atom. Spectrom. 17, 541-543.

Reiller, P., Moulin, V., 2003. Influence of organic matter in the prediction of iodine migration in natural environment. Mat. Res. Soc. Symp. Proc. 757, 565-570.

Reina, R.G., Leri, A.C., Myneni, S.C.B., 2004. Cl K-edge X-ray spectroscopic investigation of enzymatic formation of organochlorines in weathering plant material. Environ. Sci. Technol. 38, 783789

Rivail, J.-L., 1989. Éléments de chimie quantique à l'usage des chimistes. Interéditions/Éditions du CNRS, Paris.

Robens, E., Hauschild, J., Aumann, D.C., 1989. Iodine-129 in the environment of a nuclear fuel reprocessing plant: IV. ${ }^{129} \mathrm{I}$ and ${ }^{127} \mathrm{I}$ in undisturbed surface soils. J. Environ. Radioact. 9, 17-29.

Rook, J.J., 1974. Formation of haloforms during chlorination of natural waters. Water Treatment Exam. 23, 234-243.

Sarret, G., Mongenot, T., Connan, J., Derenne, S., Kasrai, M., Bancroft, G.M., Largeau, C., 2002. Sulfur speciation in kerogens of the Orbagnoux deposit (Upper Kimmeridgian, Jura) by XANES spectroscopy and pyrolysis. Org. Geochem. 33, 877-895.

Schlegel, M.L., Manceau, A., 2006. Evidence for the nucleation and epitaxial growth of $\mathrm{Zn}$ phyllosilicate on montmorillonite. Geochim. Cosmochim. Acta 70, 901-917.

Sheppard, M.I., Thibault, D.H., 1992. Chemical behaviour of iodine in organic and mineral soils. Appl. Geochem. 7, 265-272.

Sheppard, M.I., Thibault, D.H., McMurry, J., Smith, P.A., 1995. Factors affecting the soil sorption of iodine. Water Air Soil Pollut. 83, 51-67.

Shibata, Y., Yamashita, S., Masyakin, V.B., Panasyuk, G.D., Nagataki, S., 2001. 15 years after Chernobyl: new evidence of thyroid cancer. Lancet 358, 1965-1966.

Simpson, A., 2001. Multidimensional solution state NMR of humic substances: a practical guide and review. Soil Sci. 166, 795809 
Skogerboe, R.K., Wilson, S.A., 1981. Reduction of ionic species by fulvic acid. Anal. Chem. 53, 228-232.

Stern, E.A., 1988. Theory of EXAFS. In: Koningsberger, D.C., Prins, R. (Eds.), X-ray Absorption: Principles, Applications, Techniques of EXAFS, SEXAFS and XANES, vol. 92. Wiley-Interscience, New York, pp. 3-51.

Stern, E.A., 1993. Number of relevant independent points in X-ray absorption fine structure spectra. Phys. Rev. B 48, 9825-9827.

Stewart, N.G., Crooks, R.N., 1958. Long-range travel of the radioactive cloud from the accident at Windscale. Nature 182, 627-628.

Stewart, S.P., Wilkins, B.T., 1985. Areal distribution of ${ }^{129} \mathrm{I}$ in West Cumbrian Soils. J. Environ. Radioact. 2, 175-182.

Stipanicev, V., Branica, M., 1996. Iodine speciation in the water column of the Rogoznica Lake (Eastern Adriatic Coast). Sci. Total Environ. 182, $1-9$.

Sutton, R., Sposito, G., 2005. Molecular structure in soil humic substances: the new view. Environ. Sci. Technol. 39, 9009-9015.

Teo, B.K., 1986. EXAFS: Basic Principles and Data Analysis. SpringerVerlag, Berlin.

Tessier, E., Amouroux, D., Abril, G., Lemaire, E., Donard, O.F.X., 2002. Formation and volatilisation of alkyl-iodides and -selenides in macrotidal estuaries. Biogeochemistry 59, 183-206.

Truesdale, V.W., 1974. The chemical reduction of iodine in seawater. Deep-Sea Res. 21, 761-766.
Vairavamurthy, A., Wang, S., 2002. Organic nitrogen in geomacromolecules: insights on speciation and transformation with K-edge XANES spectroscopy. Environ. Sci. Technol. 36, 3050-3056.

Wagenknecht, H.A., Woggon, W.D., 1997. Identification of intermediates in the catalytic cycle of chloroperoxidase. Chem. Biol. 4, 367-372.

Warner, J.A., Casey, W.H., Dahlgren, R.A., 2000. Interaction kinetics of $\mathrm{I}_{2}(\mathrm{aq})$ with substituted phenols and humic substances. Environ. Sci. Technol. 34, 3180-3185.

Whitehead, D.C., 1974. The sorption of iodide by soil components. J. Sci. Food Agric. 25, 73-79.

Wong, G.T.F., 1991. The marine geochemistry of iodine. Rev. Aquat. Sci. 4, 45-73.

Wong, G.T.F., Cheng, X.H., 1998. Dissolved organic iodine in marine waters: determination, occurrence and analytical implications. Mar. Chem. 59, 271-281.

Wyckoff, R.W.G., 1963. Crystal Structures. Wiley, New York.

Yamada, H., Kiriyama, T., Onagawa, Y., Hisamori, I., Miyazaki, C., Yonebayashi, K., 1999. Speciation of iodine in soils. Soil Sci. Plant Nutr. 45, 563-568.

Yamaguchi, N., Nakano, M., Tanida, H., Fujiwara, H., Kihou, N., 2006. Redox reaction of iodine in paddy soil investigated by field observation and the I K-edge XANES fingerprinting method. J. Environ. Radioact. 86, 212-226. 